\title{
6-Oxopurine Phosphoribosyltransferase: A Target for the Development of Antimalarial Drugs
}

\author{
John de Jersey ${ }^{1}$, Antonín Holý ${ }^{2}$, Dana Hocková ${ }^{2}$, Lieve Naesens ${ }^{3}$, Dianne T. Keough ${ }^{1}$ and \\ Luke W. Guddat ${ }^{1, *}$
}

\author{
${ }^{I}$ The School of Chemistry and Molecular Biosciences, The University of Queensland, Brisbane, 4072, QLD, Australia; \\ ${ }^{2}$ Institute of Organic Chemistry and Biochemistry, Academy of Sciences of the Czech Republic, v.v.i. Flemingovo nam. 2, \\ CZ-166 10 Prague 6, Czech Republic; ${ }^{3}$ Rega Institute for Medical Research, Katholieke Universiteit Leuven, Minder- \\ broedersstraat 10, B-3000, Leuven, Belgium
}

\begin{abstract}
Malaria remains the most serious parasitic diseases affecting humans in the world today, resulting in 1-2 million fatalities each year. Plasmodium falciparum $(P f)$ and Plasmodium vivax $(P v)$ are the predominant causative agents. Both are responsible for widespread mortality and morbidity and are a serious socio-economic burden, especially for countries in the developing world. One of the most important defences against malaria has been the use of chemotherapeutic drugs (e.g. chloroquine, artemisinins, pyrimethamine) but these have mainly been found by serendipity. Their mechanisms was not understood at the time of their discovery and, even today, are still not unequivocal. For many of these compounds, the parasite is now resistant and, hence, there is an urgent need to develop new therapeutic drugs directed to validated targets. One metabolic pathway crucial for the survival and replication and survival of the parasite is the synthesis of the purine nucleoside monophosphates essential for the production of DNA/RNA molecules. A key enzyme in this pathway is the 6-oxopurine phosphoribosyltransferase (PRTase). The focus of this review is on the identification and characterization of inhibitors of the enzymes from both $P f$ and $P v$ as antimalarial drug leads. The acyclic nucleoside phosphonates (ANPs) appear to be excellent candidates because they are good inhibitors of the two Plasmodium enzymes, can be selective compared to the human enzyme, can arrest parasitemia in cell based assays, have low cytotoxicity to the human host cell and, because of their stable carbon-phosphorous bond, are stable within the cell.
\end{abstract}

Keywords: Malaria, acyclic nucleoside phosphonates, hypoxanthine guanine phosphoribosyl transferase.

\section{INTRODUCTION}

Plasmodium remains the deadliest parasite to humans on the planet [1]. It is a member of the phylum Apicomplexa, which is characterized by the presence of a unique organelle known as the apicoplast. The function of this organelle is speculative but it may be involved in any or all of lipid metabolism, heme and amino acid biosynthesis [2,3]. There are four major species of Plasmodium that infect humans and result in the symptoms of malaria: malariae, ovale, falciparum and vivax. In addition, $P$. knowlesi a common form of primate malaria has also been reported in humans [4] and is now an emerging strain of some concern $[5,6]$. Of these five strains, $P$. falciparum $(P f)$ and $P$. vivax $(P v)$ are the most lethal and widespread. $P v$ and $P f$ differ in their geographical distributions with $P v$ occurring widely in the tropics and extending throughout India, Eastern China, as far north as Korea and throughout Asia reaching as far as the Mediterranean Sea [7]. $P v$ is found as far south as Papua New Guinea and is prevalent in Central and South America. $P f$, by comparison, exists predominantly in Africa though it is also found in the tropical and sub-tropical areas of Central and South America and South East Asia [8].

*Address correspondence to this author at the The School of Chemistry and Molecular Biosciences, The University of Queensland, Brisbane, 4072, QLD, Australia; Tel: +61 73365 3549; Fax: +61 73365 4699;

E-mail: luke.guddat@uq.edu.au
$P f$ is reputed to infect around 500 million people per year while at least two billion live in areas at risk [7]. Over 70\% of $P f$ infections occur in the African region, while another $25 \%$ are in South East Asia. These estimated numbers are not all that different for $P v$, with at least two billion people also exposed to this strain of Plasmodium. Because of the difficulty in obtaining precise figures, the number of those who develop clinical symptoms due to $P v$ can only be estimated but is around $70-390$ million with $>80 \%$ occurring in South and Southeast Asia [7].

The clinical symptoms of $P v$ and $P f$ are different in a number of respects. While $P f$ is the most lethal, $P v$ is responsible for serious illness with recurring bouts of fever that occurs over a long term. This is due to the fact that $P v$ has the capability to lie dormant in the liver of the host. Nonetheless, both strains are responsible for a huge burden of human suffering and have a serious socio-economic impact in the countries where they are prevalent.

A number of approaches, both alone and in combination, have been adopted to try to combat malaria; these include vector control, drug therapy, indoor residual spraying, mosquito nets and bedclothes, vaccines, and improved education for those who live in areas of risk, but the problem still remains a major challenge for the medical community today. Vector control (i.e. disruption of the life cycle of the Anopheles mosquito) has proved only partially preventative and has not been sufficient to eliminate the parasite. Bed- 
netting and other such methods have been introduced as stop-gap measures and, though helpful in the short term, have not been proven to be effective long term solutions [9]. Vaccines, a hoped for cure, offers promise but despite enormous efforts, none have yet made it to the pharmacy. Reviews on the status of vector control $[10,11]$ and vaccine development [12-14] have recently been published and will not be discussed further. In the remainder of this review, the focus is on the discovery and development of therapeutic drugs to treat malaria (and other) parasitic diseases.

The use of drugs to treat malaria dates back to $\sim 1640$ when the bark of the cinchona tree was found to be effective in alleviating the symptoms of the disease. However, the mechanism of action was not understood and this remained so until 1820 when the active ingredient was identified as the alkaloid, quinine [15]. It has been suggested that quinine could lay claim to being responsible for relieving more human suffering than any other drug in history. However, it was not until 1881 that the causative agent for malaria was discovered when Charles Laveran visualized the parasite in blood. Seventeen years then elapsed before the method of transmission was identified as occurring via the Anopheles mosquito. New chemotherauptics were developed as an offshoot of attempts to produce a synthetic version of quinine. These included 8-aminoquinoline which was subsequently developed into primaquine and mepacrine [15]. Chloroquine was first synthesised in the Bayer laboratories in 1934 but it was not introduced as an antimalarial drug until 1947 because of its potential toxic side effects. Sadly, drugs of the $20^{\text {th }}$ century developed by the western-world such as quinacrine, choloroquine and primaquine are today failing to reduce the spread of the disease due to the emergence of strains of Plasmodium that have developed resistance against these therapeutic drugs [9]. Even today, for many of the currently used drugs, the mechanism of action is still the subject of conjecture. For example, the action of quinine, chloroquine and its derivatives is poorly understood, but it is believed they work by preventing polymerization of the toxic heme [16], which is released as a byproduct of hemoglobin digestion. Resistance by the parasite to chloroquine arises due to mutations in the sequence of the chloriquine resistance transporter [17].

Several other antimalarial drugs have been discovered and developed over the years. These are shown in Fig. (1). Most if not all of these have problems associated with their use (i.e. resistance [9] and cost-effectiveness), further highlighting the need to discover new antimalarial targets and therapeutic agents. Artemisinin, a natural product from the leaves of the herb, sweet wormwood, Artemisia annua, was isolated in the 1960s. The leaves of such plants had been in use in China for more than a thousand years as a treatment for malaria but, just like the bark from the cinchona tree, the active ingredient was not known nor was its mechanism of action proposed until recent times. However, as with most drugs, problems of expense, unknown side effects and increasing resistance must now be overcome.

Today, with the sequencing of the $P v$ [18] and $P f$ genomes [19] and through the use of advanced scientific approaches such as the screening of large chemical libraries [20], we are now in an unprecedented position to design and develop drugs to specifically target and treat malaria. Advances in structural biology have facilitated the determination of the three-dimensional structure of proteins essential for the life cycle of the parasite. This is a significant factor in allowing us to understand the mechanisms by which drugs interact with their target and how resistance can develop. Based on these advances in knowledge and technologies, it is envisaged that new generations of therapeutic agents will not only be effective in the short term but have the potential to eradicate malaria.

The main focus in new drug development against malaria has, to date, centered on $P f . P v$ has been sometimes been referred to as the neglected disease, not because of its devastating effect on the health of the population, but because it was reputed not to be as lethal as $P f$ [21]. However, with increasing global awareness, attention is now turning to the very serious health and socio-economic burden caused by this species of the disease. In the development of new antimalarials consideration needs to be given to drugs that can control both $P f$ and $P v$. This aspect is an important focus of the current review. Several other factors that are specific to the development of antimalarials also need to be considered. These include the need for drugs to:

1) be cost effective, as those regions most highly affected are predominantly in developing countries;

2) target proteins that are specific to the parasite's survival but are non-toxic to the host cell;

3) target proteins that would be difficult for the parasite to mutate without compromising its own existence;

4) be able to cross the membranes of both the erythrocyte (where the red blood cell stage is targeted) and the parasite; and

5) be stable within the cell to be effective.

For optimal drug discovery, differences between the metabolism of the parasite and its host cell should be exploited. Adopting this rationale minimizes the difficulty of finding a drug which binds tightly and specifically to a parasite protein but much less so to the homologous human protein. This approach is being exploited to discover inhibitors that target a broad range of proteins, and especially those found in the apicoplast [22], an organelle unique to the parasite. An important metabolic difference between the human host and the parasite lies in their ability to synthesise the purine nucleoside monophosphates essential for DNA/RNA production. Like all protozoan parasites, $P f$ and $P v$ are auxotrophic for the purine ring and depend on the 6-oxopurine phosphoribosyltransferase (PRTase) for the synthesis of the nucleoside monophosphates. Humans, however, are able to make purine rings from small molecules and thus are not totally dependent on the salvage pathway. The precise role of 6-oxopurine PRTase in metabolism will be discussed in the next section and is one of the focuses of this review.

The parasite needs to synthesise large amounts of nucleic acids within the 48-hour life of the erythrocytic stage of their development, when the parasites grow and divide rapidly. After multiplying within an erythrocyte, the parasite ruptures the cell wall of the erythrocyte releasing toxic metabolites into the host. Thus, drugs targeted at disrupting the machin- 
<smiles>C=CC1CC2CCN1CC2[C@H](O)c1ccnc2ccc(OC)cc12</smiles>

Quinine $^{\mathrm{a}}$<smiles>CCN(CC)CCCC(C)Nc1ccnc2cc(Cl)ccc12</smiles>

Chloroquine<smiles>O=C1C(O)=C(C2CCC(c3ccc(Cl)cc3)CC2)C(=O)c2ccccc21</smiles>

(plus proguanil) $^{\mathrm{d}}$<smiles>O[C@H](c1cc(C(F)(F)F)nc2c(C(F)(F)F)cccc12)C1CCCCN1</smiles>

Mefloquine (Larium) ${ }^{a}$<smiles>COc1cc(NC(C)CCCN)c2ncccc2c1</smiles>

$(R, S)$-Primaquine ${ }^{b}$<smiles>C[C@H]1CC[C@H]2[C@@H](C)C(=O)O[C@@H]3O[C@]4(C)CCC1[C@@]32OOO4</smiles>

Artemisinin ${ }^{\mathrm{e}}$<smiles>CCN(CC)Cc1cc(Nc2ccnc3cc(Cl)ccc23)ccc1O</smiles>

Amodiaquine ${ }^{a}$<smiles>CCCCN(CCCC)CCC(O)c1cc2c(Cl)cc(Cl)cc2c2cc(C(F)(F)F)ccc12</smiles>

Halofantrine ${ }^{\mathrm{c}}$<smiles>CCC[C@@H]1C[C@@H](C(=O)N[C@H](C(C)Cl)[C@@H]2C[C@H](SC)[C@@H](O)[C@H](O)[C@H]2O)N(C)C1</smiles>

Clindamycin ${ }^{f}$<smiles>C[C@H]1c2cccc(O)c2C(=O)C2=C(O)[C@]3(O)C(=O)C(C(N)=O)C(O)C(N(C)C)[C@@]3(C)[C@H](O)[C@]21C</smiles>

Doxycycline ${ }^{g}$<smiles>COc1c(O)ncnc1NS(=O)(=O)c1ccc(N)cc1</smiles>

Sulfadoxin ${ }^{\mathrm{h}}$<smiles>CCc1nc(N)nc(N)c1-c1ccc(Cl)cc1</smiles>

Pyrimethamine $^{\mathrm{h}}$

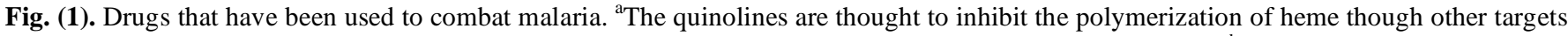

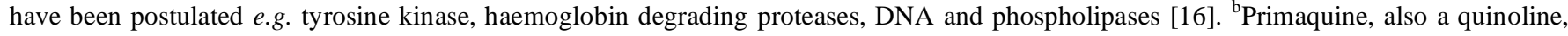
should not be administered to patients with a glucose-6-phosphate dehydrogenase or NADH methemoglobin reductase deficiency [65]. ${ }^{\mathrm{C}} \mathrm{Ha}$ lofantrine may have a similar mechanism of action to the quinolines [66]. ${ }^{\mathrm{d}}$ Atovaquone is a broad spectrum drug that inhibits mitochondrial electron transport at the cytochrome bc1 complex and collapses mitochondrial membrane potential [67]. ${ }^{\mathrm{e}}$ Artemisinins have a highly reactive endoperoxide moiety that is thought to be critical for their mode of action $[68,69] .{ }^{\mathrm{f}} \mathrm{Clindamycin}$ inhibits bacterial protein synthesis by stopping ribosomal translocation by binding to the $28 \mathrm{~S}$ rRNA. It is derivative of the natural antibiotic, lincomycin [70]. ${ }^{\mathrm{g}}$ Doxycycline impairs the progeny of the apicoplast genes resulting in their abnormal cell division [71]. ${ }^{\mathrm{h}}$ Sulfadoxin and Pyrimethamine are used in combination to inhibit the production of enzymes used in the synthesis of folic acid [72].

ery of cell replication will not only exert its effects on the health of those infected but will also help to eradicate the parasite since it will not be available for further infection of the red blood cells nor for transmission to the Anopheles mosquito.

6-Oxopurine PRTase can be targeted in two ways for drug discovery. The first is to use the catalytic properties of the enzyme to convert exogeneous base analogs to mononucleotides toxic to the parasite while the second is direct inhibition of the enzyme itself [22-24]. 6-Oxopurine PRTases exist in all organisms and have common structural and catalytic features but there are significant differences in substrate specificity, catalytic efficiency and importance in the life cycle of the particular organism. It is proposed that inhibitors of the malarial enzymes could also be inhibitors of the 6oxopurine PRTases found in other disease causing protozoan parasites or bacteria. In the case of bacterial infection, it has been suggested that 6-oxopurine PRTase inhibitors have potential to treat stomach ulcers that result from infection by Helicobacter pylori [23]. Thus, 6-oxopurine PRTase inhibi- 
tors have the potential to be broad-spectrum antimicrobial drugs.

For the remainder of this review, the focus is on the assessment of the 6-oxopurine PRTases as targets for the development of antimalarial drugs directed against $P f$ and $P v$. Here we will discuss; (i) the metabolic pathways available to $P f$ and $P v$ to produce the essential purine nucleotides; (ii) what is known about the overall chemistry of the reaction catalysed by the 6-oxopurine PRTases; (iii) the evidence that suggests 6-oxopurine PRTase is an excellent target for antimalarial drug discovery; (iv) the discovery of substrate and product analogs of 6-oxopurine PRTases that arrest parasitemia in cell culture; and (v) a comparison of the threedimensional structures of several 6-oxopurine PRTases and the implications for drug discovery.

\subsection{The Metabolic Pathway Available in $P f$ and $P v$ for the Synthesis of the Purine Nucleoside Monophosphates}

A difference in metabolism between the host cell and protozoan parasites is their ability to synthesise the purine nucleoside monophosphates. Mammals possess two pathways to produce these metabolites: de novo from small molecules and salvage of preformed purine bases. Humans rely on both pathways but, although inherited mutations in the gene coding for HGPRT can have deleterious symptoms, deficiency by up to $97 \%$ in activity can readily be treated by allopurinol [24]. This is because the clinical symptom due to the partial loss of HGPRT activity is the over-production of uric acid. Allopurinol (1,5-dihydro-4H-pyrazolo[3,4$d$ ]pyrimidin-4-one) is an analog of $\mathrm{Hx}$ in which the nitrogen in the 7-position is replaced by carbon and the carbon in the 8 -position is replaced by nitrogen. This compound was originally developed at Burroughs Wellcome in the 1940s and led to the synthesis of drugs such as acyclovir, trimethoprim and the early antineoplastic compounds, thioguanidine and 6-mercaptopurine (6-MP). Allopurinol is not only an inhibitor of xanthine oxidase but it is also a substrate. After administration, it is rapidly converted to oxipurinol (pyrazolo[3,4-d]pyrimidine 1-N-ribonucleotide). Oxipurinol has a longer half-life than allopurinol itself and it is also an inhibitor of xanthine oxidase. The basic effect of the administration of allopurinol is, therefore, to decrease the concentration of uric acid produced from the 6-oxopurine bases, hypoxanthine and xanthine, by xanthine oxidase. One of the problems in drug design is the possibility of toxic side-effects to the host, but the wealth of data on deficient human HGPRT suggests that a weak to moderate inhibitor of human HGPRT should not prove to be toxic to the host.

All protozoan parasites studied to date are auxotrophic for the purine base and have to rely on the transport of preformed metabolites from the host. In $P f$, there are three key enzymes involved in the salvage of purine nucleobases and nucleosides transported from the host cell Fig. (2). These are adenosine deaminase (ADA), purine nucleoside phosphorylase (PNP) and hypoxanthine-guanine-xanthine phosphori-

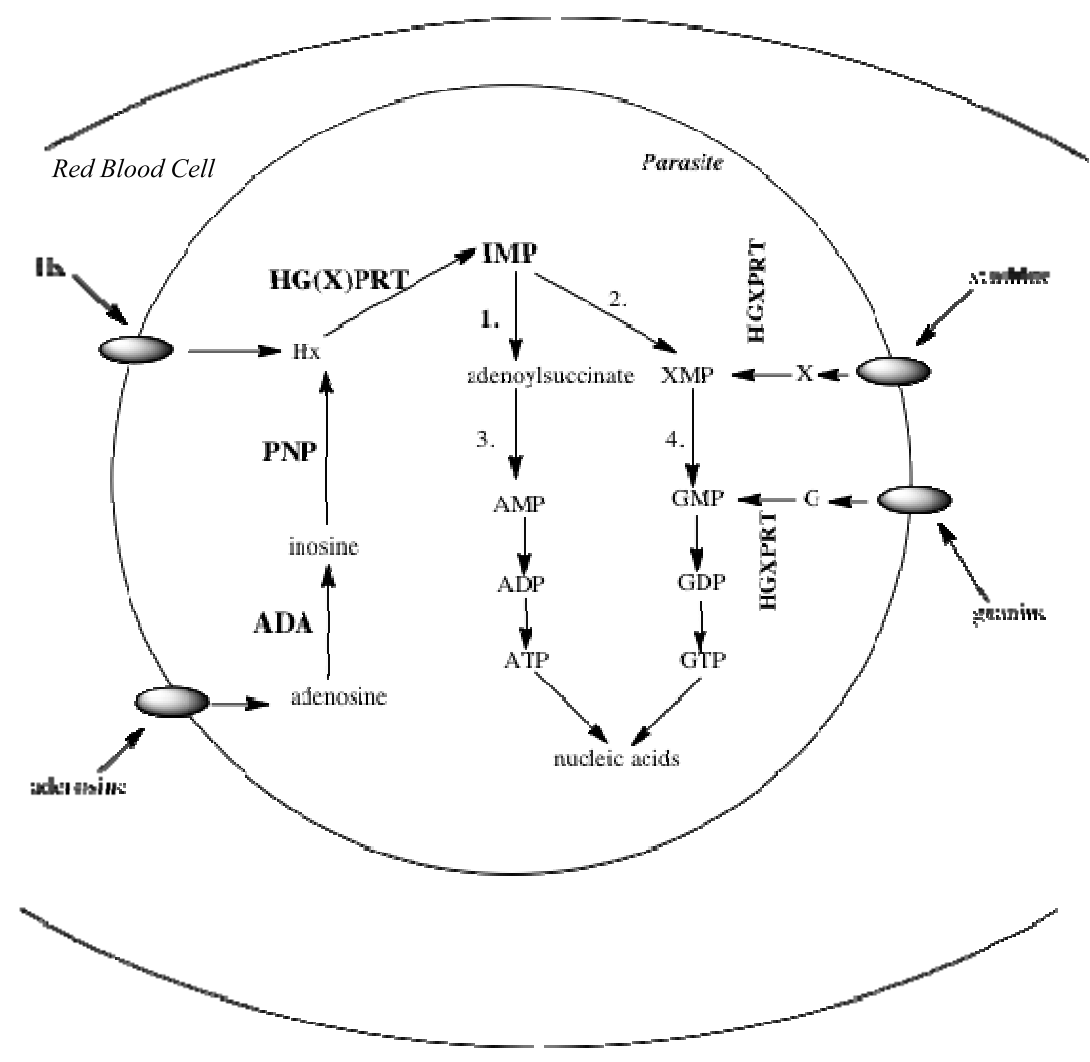

Fig. (2). The metabolic route for purine nucleic acid synthesis in $P f$ (and $P v$ ). ADA, adenosine deaminase; PNP, purine nucleoside phosphorylase; (1) adenylsuccinate synthase; (2); IMP dehydrogenase; (3) adenylsuccinate lyase; and (4) GMP synthase. 
bosyltransferase (HGXPRT) (i.e. 6-oxopurine PRTase). ADA converts adenosine transported across the parasite membrane to inosine, which is converted to hypoxanthine (Hx) by PNP. HGXPRT then catalyses the formation of IMP from Hx. HGXPRT also synthesises IMP directly from $\mathrm{Hx}$ transported across the parasite cell membrane Fig. (2). Hypoxanthine is a crucial source of the purines within the parasite and is the usual nutritional additive to the media in $P f$ grown in cell culture. The external concentration is usually around $370 \mu \mathrm{M}$. One piece of evidence that supports the importance of $\mathrm{Hx}$ in the purine metabolism of $P f$ is the fact that supplementation of media with $100-400 \mu \mathrm{M} \mathrm{Hx}$ results in a 3-4 fold increase in parasite yield [25]. The importance of $\mathrm{Hx}$ as a central metabolite on which $P f$ depends for survival is further demonstrated by the fact that increasing the concentration of xanthine oxidase in the media [26] (which effectively reduces the amount of $\mathrm{Hx}$ available to the parasite by converting it to uric acid) inhibits the growth of $P f$. This inhibition can be reversed by adding excess Hx back to the media [26].

The specific activity of the 6-oxopurine PRTase for hypoxanthine in $P f$ is of the order of 60 -fold higher than that of human HGPRT in the erythrocyte emphasizing its importance in the parasite's metabolism. The high concentration of HGXPRT in $P f$ cells in culture has also been demonstrated by confocal microscopy Fig. (3).

Gero et al. [27] were the first to demonstrate that nucleosides are actively transported into the parasite via a membrane protein. Sequencing of the $P f$ genome has revealed four proteins that could be responsible for the transport of purine nucleobases and nucleosides into the parasite. These have been identified as PfNT1, 2, 3 and 4 [28-30]. However, to date, only PfNT1 has been characterized [29,31,32]. The concentration of the nucleobases and nucleosides in the host cell that are available to the parasite for their source of purines are given in Table $\mathbf{1}$.

The high levels of hypoxanthine in red blood cells further suggests that it is a primary source of nucleoside monophosphates for the invading parasite (Table 1). Adenosine is present in high concentrations in the red blood cell and this can be converted to AMP by adenosine kinase (AK), which by deamination would give IMP. However, sequencing of the $P f$ genome shows that there is no cDNA coding for $\mathrm{AK}$ in the

A

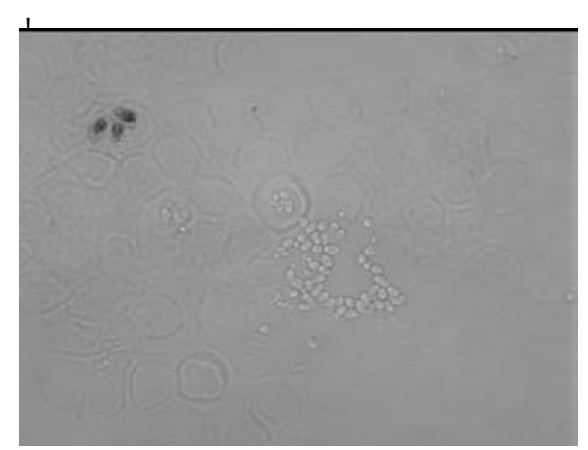

parasite and thus the sole route for IMP synthesis is via the three enzymes; ADA, PNP and HGXPRT [33]. There was a possibility that a second purine salvage enzyme, adenine PRTase (APRT), could provide a route for the synthesis of AMP. Reyes et al. [34] did measure activity of this enzyme in isolated parasites but the level was around 1500-fold less than for HGPRT suggesting that its role in parasite metabolism was minor. Later evidence, however, revealed that there is no gene coding for APRT in P. falciparum [33] and the activity measured was probably due to contamination with the red blood cell APRT. Thus, the pivotal enzyme in producing the nucleoside monophosphates is HGPRT and the central metabolite for their production is IMP.

Table 1. The Concentration of Purine Nucleobases and Purine Nucleosides in Human Red Blood Cells

\begin{tabular}{|c|c|}
\hline Metabolite & Concentration $(\mu \mathbf{M})$ \\
\hline \hline Hypoxanthine & $8.2 \pm 1.3[73]$ \\
\hline Xanthine & $2.5 \pm 0.6[73]$ \\
\hline Adenine & $0.3 \pm 0.15[73]$ \\
\hline Adenosine & $0.6 \pm 0.2[73]$ \\
\hline
\end{tabular}

It has recently been reported that, contrary to the assumption that anionic, phosphorylated metabolites are unable to be transported across the cell membrane, AMP is able to cross into $P f$ from the host cell [35]. Thus far, a membrane transporter has not been identified though is has been established that PfNT1 is unable to transport AMP [35]. The observation that AMP is transported is based on two lines of evidence. Firstly, inhibitors of the parasite's PNP and ADA result in a reduction in cell growth which can be rescued by high concentrations of adenosine but this rescue is significantly reduced if the human $\mathrm{AK}$ enzyme is inhibited as $\mathrm{AK}$ provides the source of AMP in the erythrocyte [35]. The second piece of evidence in support of AMP transport is the appearance of radiolabelled Hx within the parasite cell after exogenous supply of radiolabelled AMP [35]. This is presumably by the action of two enzymes, AMP deaminase which converts AMP to IMP and then by HGXPRT which then produces Hx.

$\mathbf{B}$

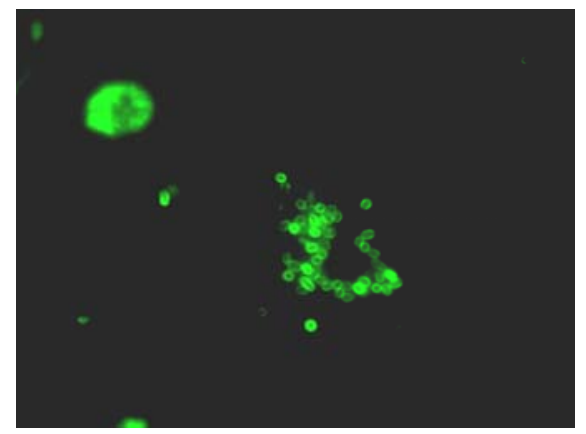

Fig. (3). Localisation of PfHGXPRT in parasite cells grown in erythrocyte culture. A. Non-stained region showing the rupture of a red blood cell by parasites. B. Fluorescence image of the same region incubated with an antibody against PfHGXPRT and visualized with a secondary antiserum conjugated to FITC. 


\subsection{The Reaction Catalysed by the 6-Oxopurine PRTases}

The 6-oxopurine PRTases belong to a group of ten enzymes which are responsible for the synthesis of purine nucleotides, pyrimidine nucleotides, NAD and, in bacteria and lower eukaryotes, histidine and tryptophan [36]. The reaction catalysed by this enzyme is shown in Fig. (4). For catalysis to occur a divalent metal ion must be present and this is usually $\mathrm{Mg}^{2+}$ in vivo though other divalent metal ions such as $\mathrm{Mn}^{2+}$ are also effective substitutes [37]. The mechanism of action of human HGPRT is ordered: $P$ Rib- $P P . \mathrm{Mg}^{2+}$ binds first followed by the purine base [38]. Pyrophosphate then dissociates from the complex and the nucleoside monophosphate is released in the rate-limiting step. For the enzymes from Tritrichomonas foetus [39], Leishmania donovani [40], Schistosoma mansoni [41] and Trypanosoma cruzi [42], this mechanism is also sequential and it is therefore likely that all the 6-oxopurine PRTases operate in a similar fashion.

It has been proposed that the mechanism could proceed by an $\mathrm{S}_{\mathrm{N}} 2$-type displacement due to the inversion of configuration at the anomeric carbon of $P$ Rib- $P P$. However, evidence strongly supports a two-step $S_{N} 1$-mechanism [43] with the formation of an unstable intermediate ribooxycarbenium ion Fig. (5).

A common feature in the structures of the 6-oxopurine PRTases is the presence of a large flexible loop consisting of between 10-20 amino acid residues (depending on the particular enzyme involved) that closes over the active site during the catalytic reaction. It has been hypothesised that the role of this loop is to help stabilise the transition state and to protect the bound $P$ Rib- $P P . \mathrm{Mg}^{2+}$ from hydrolysis by bulk solvent [44]. The role of this loop in structure-based drug design is discussed later.

\subsection{A Comparison of the Kinetic Properties of 6- Oxopurine PRTases from Human, P. Falciparum, $P$. Vivax and E. Coli Cells}

The 6-oxopurine PRTases from different organisms can be classified based on their different specificities for the three naturally-occurring purine bases, guanine, hypoxanthine and xanthine (Table 2). Thus, while some enzymes can use all three bases (though with different catalytic efficiencies), some are able to use only two while others have a distinct preference for one base alone (Table 2).

Many organisms possess only one 6-oxopurine PRTase and this appears to be sufficient to synthesise all the essential

(a)

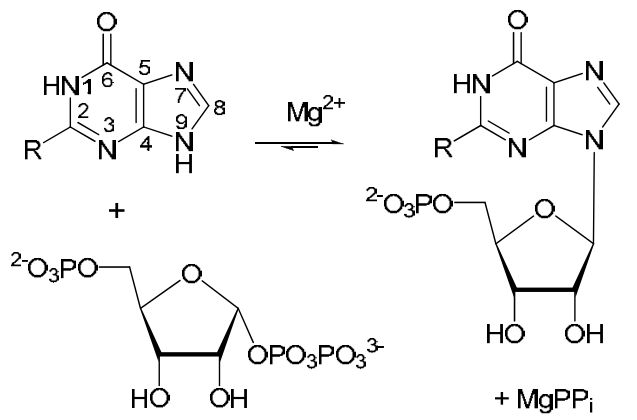

nucleoside monophosphates that they require for survival. These organisms include humans, $P f$ and $P v$. However, $T$. gondii, L. donavani and E. coli possess two 6-oxopurine PRTases with differing base specificities. Though there are distinct differences in the preference for the 6-oxopurine bases, all these 6-oxopurine PRTases contain a common feature, which is their ability to bind the first substrate to enter the active site, $P$ Rib- $P P \mathrm{Mg}^{2+}$. Because of the relatively small differences in the $\mathrm{K}_{\mathrm{m}}$ values for $P$ Rib- $P P$ between all these enzymes ( 25-60 $\mu \mathrm{M}$; Table 3 and between $25-32 \mu \mathrm{M}$ for the enzymes from $L$. donavani, $G$. lamblia, $T$. gondii $[42,45,46]$, it could be assumed that $P$ Rib- $P P$ binds in a highly conserved region in their structures. A comparison of the sequences of the enzymes in this region (Section 1.6) confirms this. A comparison of the kinetic constants of the 6oxopurine PRTases from human, Plasmodium and E. coli cells is given in Table $\mathbf{3}$.

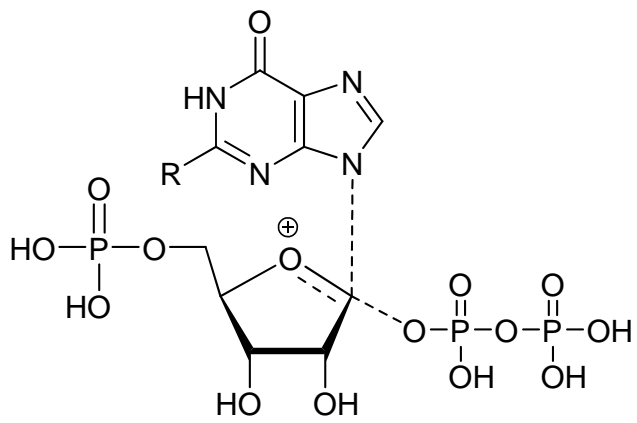

Fig. (5). Structure of the transition state in the reaction catalysed by the 6-oxopurine PRTases. $\mathrm{R}$ is $-\mathrm{NH}_{2}$ (guanine) or $-\mathrm{H}$ (hypoxanthine).

One of the most striking differences between the 6oxopurine PRTases is in their $\mathrm{k}_{\text {cat }}$ values for their respective nucleobase substrates. The bacterial enzymes are the most efficient having values around 4-7 times higher for the preferred purine base compared to that for the human enzyme. In comparing human HGPRT with PfHGXPRT and $P v$ HGPRT, this ratio is between 50-90 and 20-34, respectively. An explanation for these differences could be that parasite enzymes do not need to have a high turnover rate as these are present in much higher levels in Plasmodium compared to human erythrocytes where HGPRT is only expressed once in the life-time of the red blood cell $\left(t_{1 / 2}=120\right.$ days).

(b)

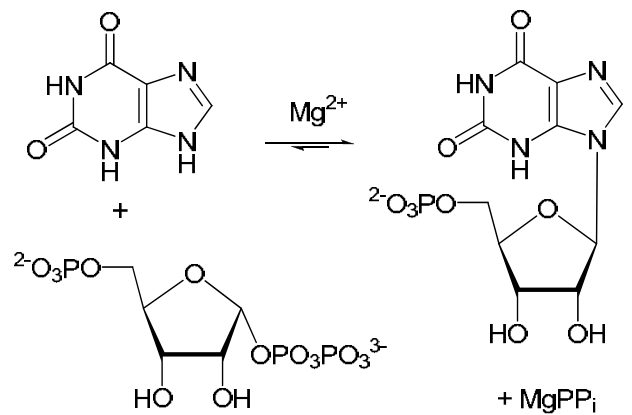

Fig. (4). The reactions catalysed by the 6-oxopurine PRTases. The naturally occurring purine bases are guanine $\left(\mathrm{R}^{\text {is }}-\mathrm{NH}_{2}\right)$, hypoxanthine $(\mathrm{R}$ is $-\mathrm{H})$ and $x$ anthine $(\mathrm{R}=\mathrm{O})$. 
Table 2. Purine Base Specificity for the 6-Oxopurine PRTases from Different Organisms ${ }^{\text {a }}$

\begin{tabular}{|c|c|}
\hline Name & Source \\
\hline \hline HGXPRT & T. gondii [74,75], T. foetus [39], P. falciparum [76] \\
\hline HGPRT & Mammals [77], L. donovani [78], P. vivax [47] \\
\hline HPRT & E. coli $[79,80]$ \\
\hline XGPRT & L. donovani $[40,78]$, E. coli $[79,80], T$. gondii $[74,75]$ \\
\hline GPRT & G. lamblia [81,82] \\
\hline
\end{tabular}

${ }^{a}$ The abbreviations indicate base specificity

Both $P f$ and $P v$ enzymes bind Hx more tightly than guanine as would be expected if hypoxanthine is the primary source of nucleoside monophosphates, whether this is by direct transport or via ADA and PNP Fig. (2). However, though PfHGXPRT distinguishes between guanine and hypoxanthine in terms of catalytic efficiency $\left(\mathrm{k}_{\mathrm{cat}} / \mathrm{K}_{\mathrm{m}}\right)$,
$P v$ HGPRT uses both these bases equally well. In comparison, the human enzyme prefers guanine as its substrate. The $P f$ genome is $80 \%$ AT compared with $P v$ which is $55 \%$ AT. Thus, $P v$ has a higher requirement for guanine mononucleotides than does $P f$.

Another difference between the $P f$ and $P v$ enzymes is their ability to use xanthine [47]. This is surprising given that these two enzymes have $77 \%$ amino acid sequence identity (see Section 1.6). Pf may have evolved to use xanthine during its life-cycle in the mosquito. However, $P v$ does not have this requirement. Whether this ability to use xanthine occurred later or earlier in the evolutionary tree is unknown, but an understanding of this difference in metabolism between the two strains warrants further investigation.

There are other differences between the human, $P f$ and $P v$ enzymes and one of these is in the $\mathrm{K}_{\mathrm{i}}$ values for the mononucleotide product. $P v$ HGPRT binds GMP and IMP more weakly than the $P f$ or human enzymes. For $P v$ HGPRT, the $\mathrm{K}_{\mathrm{i}}$ for IMP is $62 \mu \mathrm{M}$ and for GMP, this value is $26.1 \mu \mathrm{M}$ [47]. PfHGXPRT binds these compounds more tightly, with $\mathrm{K}_{\mathrm{i}}$ values of $3.6 \pm 1 \mu \mathrm{M}$ and $10 \pm 2 \mu \mathrm{M}$, respectively. The human enzyme is more similar to PfHGXPRT in this respect $\left(\mathrm{K}_{\mathrm{i}}\right.$ for IMP is $5.4 \pm 1.2 \mu \mathrm{M}$ and, for GMP, $5.8 \pm 0.2 \mu \mathrm{M}$ ). $E$.

Table 3. Kinetic Constants for Human, Plasmodium and E. coli 6-Oxopurine PRTases

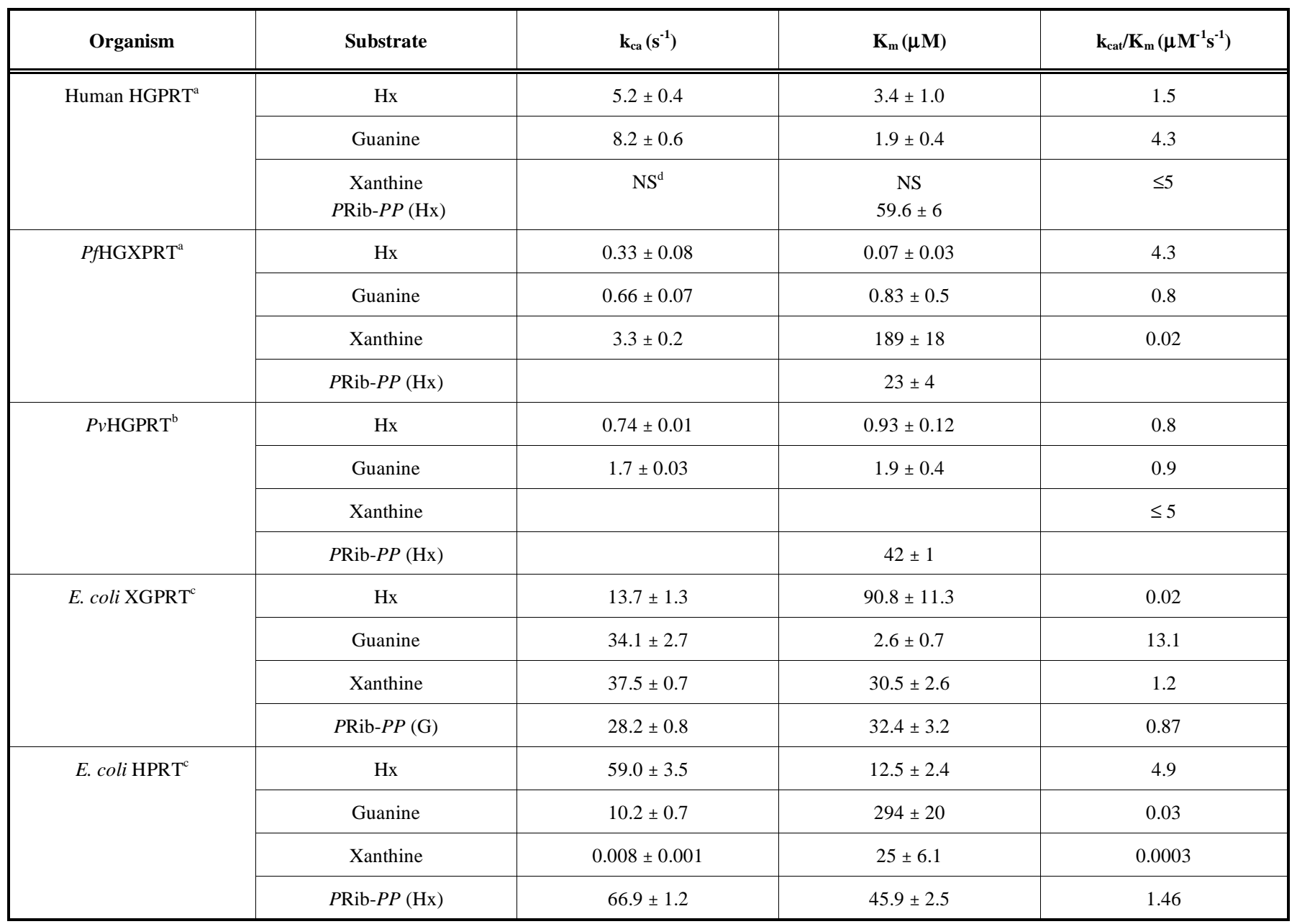

${ }^{\mathrm{a}}$ Keough et al.,[76] ${ }^{\mathrm{b}}$ Keough et al.,[47] ${ }^{\mathrm{c}}$ Guddat et al.,[80] ${ }^{\mathrm{d}} \mathrm{NS}=$ not a substrate. 
coli XGPRT binds GMP tightly with a $\mathrm{K}_{\mathrm{i}}$ value of $4.6 \pm 0.6$ $\mu \mathrm{M}$ though HPRT binds the product of the reaction very weakly and has a $\mathrm{K}_{\mathrm{i}}$ for IMP of $247 \pm 55 \mu \mathrm{M}$ (unpublished data).

\subsection{Base Analogs as Potential Drug Leads}

The use of base analogs which could be good substrates for the malarial 6-oxopurine PRTases but weak for the human enzyme has been considered as a potential pathway to drug development. Such purine base analogs would be converted by the 6-oxopurine PRTase to the corresponding mononucleotide which, after incorporation into nucleic acids, would be toxic to the cells. This is a similar mechanism of action to that proposed for the anti-cancer agent, 6mercaptopurine [48].

A comparison of the kinetic constants for a number of purine base analogs is given in Table 4. Some of these purine substrate analogs discriminate between the human and $P f$ enzymes with relative catalytic efficiency up to 370 in fa- vour of the $P f$ enzyme (8-azahypoxanthine) but only 30 -fold for the $P v$ HGPRT in comparison with human HGPRT (6thioguanine) [49]. These differences in base specificity provide evidence that, although catalysing a similar reaction, differences in the active site exist between the three enzymes which can be exploited for drug design. In addition, the study demonstrates that the purine binding site can accept molecules other than the three naturally occurring 6oxopurines.

Further studies have shown that these compounds are effective in arresting cell growth of the $P f$ parasite in culture, with $\mathrm{IC}_{50}$ values as low as $1 \mu \mathrm{M}$ (Table 5). At this time, $P v$ cannot be maintained in culture, so $P f$ is the only model for testing the effectiveness of such compounds in cell culture. For two compounds tested in P. berghei ANKA in CD1 mice (mice are not infected by falciparum or vivax), it was shown that 6-mercaptopurine reduced parasitemia by $47 \%$ and 8 azaguanine by $32 \%$ [47]. This appears to be a reflection of the ability of the 6-oxopurine PRTase in P. berghei to convert these bases into toxic metabolites.

Table 4. Comparison of the Catalytic Efficiencies $\left(k_{\text {cat }} / K_{\mathrm{m}}\right)$ of the Purine base Analogs for Human $P f$ and $P v$ 6-Oxopurine PRTases ${ }^{\mathrm{a}, \mathrm{b}}$

\begin{tabular}{|c|c|c|c|}
\hline \multirow{2}{*}{ Purine base Analog } & \multicolumn{3}{|c|}{$k_{\text {cat }} / K_{\mathrm{m}}\left(\mu \mathbf{M}^{-1} \mathbf{s}^{-1}\right)$} \\
\hline & Hu & $P f$ & $P v$ \\
\hline 6-mercaptopurine & 2.0 & 20 & 0.5 \\
\hline 6-thioguanine & 0.05 & 1.0 & 1.4 \\
\hline 6-thioxanthine & $\leq 4$ & 0.005 & $\mathrm{ND}^{\mathrm{c}}$ \\
\hline 2-amino-6-chloropurine & $\leq 0.00013$ & 0.007 & $\leq 0.0001$ \\
\hline 8-azahypoxanthine & 0.001 & 0.37 & 0.003 \\
\hline 8 -azaguanine & 0.005 & 0.4 & 0.004 \\
\hline allopurinol & 0.003 & 0.06 & 0.0006 \\
\hline
\end{tabular}

${ }^{a}$ Keough, et al. [49], ${ }^{b}$ Keough, et al. [47] ${ }^{\mathrm{c}} \mathrm{ND}=$ not determined

Table 5. Effect of Purine base Analogs on the uptake of $\left[{ }^{3} \mathbf{H}\right]$ hypoxanthine into Parasite Nucleic Acids and on the Growth of $P$. falciparum in Erythrocyte Cell Culture ${ }^{\mathrm{a}}$

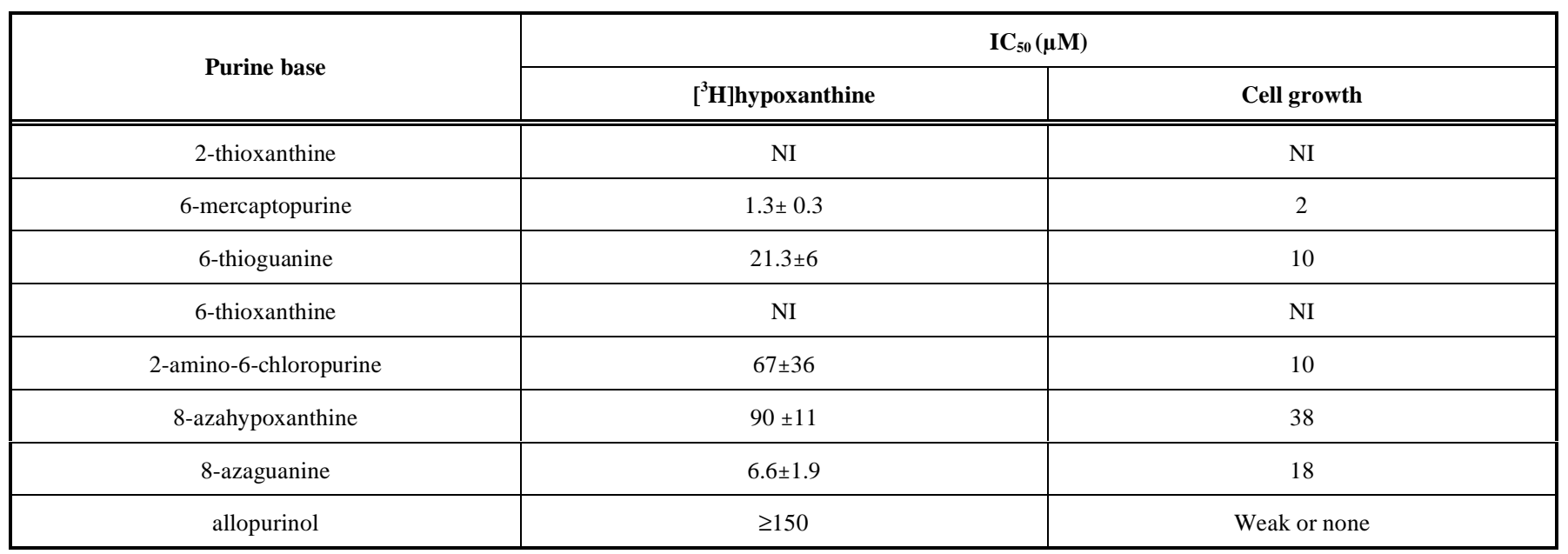




\subsection{Inhibitors of the Malarial Enzymes and Comparison with the Human Enzyme}

The first inhibitors with low $\mathrm{K}_{\mathrm{i}}$ values for both human HGPRT and PfHGXPRT were the immucillin 5'-phosphates synthesized by Schramm and his colleagues [50]. Their structure is based on mimicing the transition state of the catalytic reaction of the 6-oxopurine PRTases Fig. (5). These elegantly designed compounds, the (1S)-1-(9-deazaguanin-9yl)-1,4-dideoxy-1,4-imino-D-ribitol 5'-phosphates (immucillin 5'-phosphates) Fig. (6), bind to the human and $P f$ enzymes with $\mathrm{K}_{\mathrm{i}}^{*}$ values of $1-4 \mathrm{nM}$ [50]. These compounds only bind tightly in the presence of $\mathrm{PP}_{\mathrm{i}}$ and $\mathrm{Mg}^{2+}$. An X-ray crystal structure of this complex shows the interactions that occur between the inhibitor and amino acid side chains and backbone atoms present in the active site [51]. One characteristic of these compounds is that, on binding, they cause the flexible loop to close firmly over the active site [51]. This could be an important factor contributing to their low $\mathrm{K}_{\mathrm{i}}$ values.

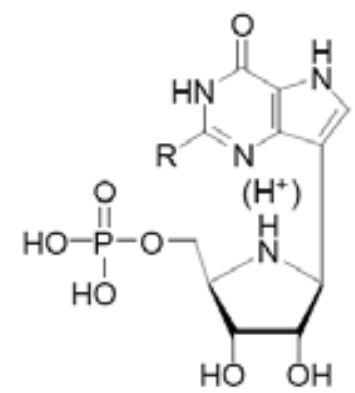

Fig. (6). Structure of the immucillin $5^{\prime}$-phosphates. $\mathrm{R}$ is $-\mathrm{NH}_{2}$ (guanine) or $-\mathrm{H}$ (hypoxanthine).

A second class of compounds that inhibit the human, $P f$ and $P v$ enzymes is the acyclic nucleoside monophosphonates (ANPs). Their structure is based on those of the antiviral drugs such as adefovir [52], which target the DNA polymerase of the virus to prevent replication. These molecules possess excellent pharmacokinetic properties and they have low cytotoxicity toward human cells [53]. Thus, it was hypothesized that such compounds with a 6-oxopurine base could inhibit the parasite 6-oxopurine PRTases and prove efficacious as antimalarial drugs Fig. (7), Tables 6 and 7.

The ANPs were subsequently tested for their ability to inhibit the growth of $P f$ in cell culture. The original observation that ANPs could be effective against $P f$ was first made in 1999 [54] and showed that (S)-9-(3-hydroxy-2-phosphonomethoxypropyl)guanine inhibited the growth of $P f$ in cell culture with an $\mathrm{IC}_{50}$ value of $4.3 \pm 0.9 \mu \mathrm{M}$. However, the mechanism of action was unknown at that time. The most likely target for these compounds is identified as HGXPRT which now makes possible the development of new compounds by rational structure-based design approaches.

Currently synthesised ANPs do not bind to the 6oxopurine PRTases as tightly as the immucillin 5' phosphates. However, as drug leads they have four strengths:

1) They can exhibit selectivity for the $P f$ and $P v$ enzymes over the human counterpart (Table 6);

2) They can arrest the growth of $P f$ in cell culture and have $\mathrm{IC}_{50}$ values as low as $100 \mathrm{nM}$, showing that they can be transported across the red blood cell and $P f$ membranes though the mechanism of transport has yet to be defined;

3) Many have low cytotoxicity in human A549 and U251 cell lines suggesting that they have minimal, if any, inhibitory effect on cellular enzymes (including human HGPRT);

4) They possess a stable carbon-phosphorus bond between the phosphonate group and the linker to the purine base. Thus, these molecules are not susceptible to hydrolysis within the cell.
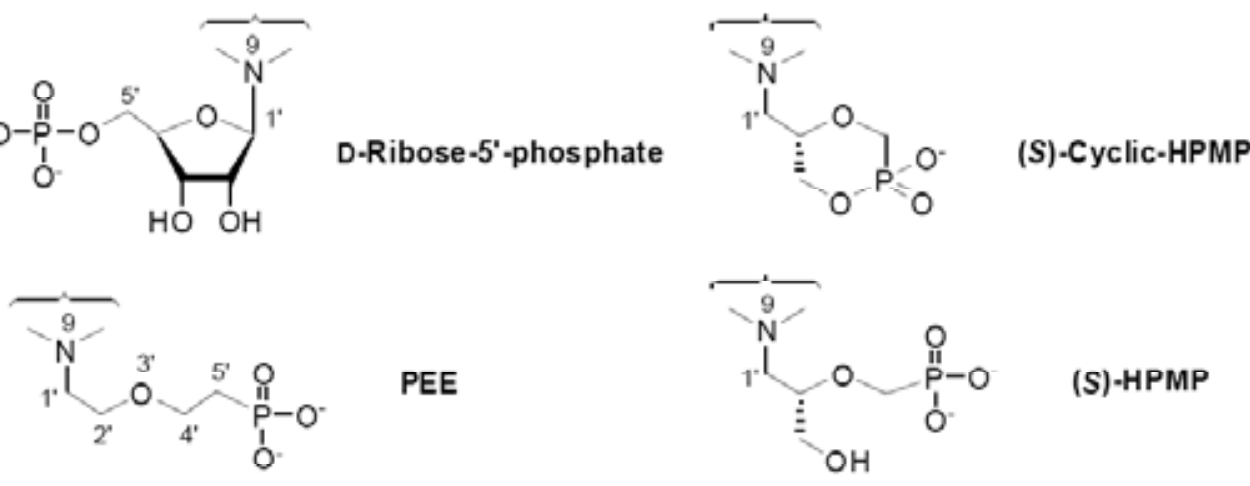

PEE

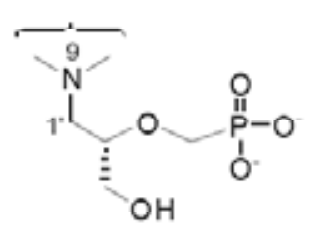

(S)-HPMP

PME

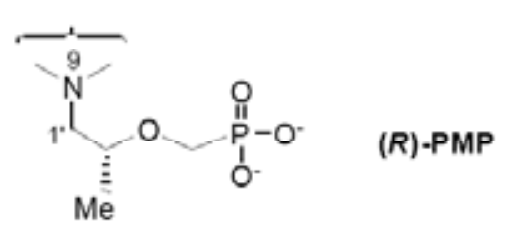

Fig. (7). Structures of the phosphonate moieties (Table 7) and the D-ribose 5'-phosphate of the purine nucleoside monophosphates. 
Table 6. Inhibition of the $P f$ and Human 6-Oxopurine PRTases by ANPs ${ }^{\text {a }}$

\begin{tabular}{|c|c|c|c|}
\hline \multirow{2}{*}{ Base } & \multirow{2}{*}{ Phosphonate Tail } & \multicolumn{2}{|c|}{$\mathbf{K}_{\mathbf{i}}(\boldsymbol{\mu} \mathbf{M})$} \\
\hline & & PfHGXPRT & Human HGPRT \\
\hline Guanine & Ribose-5'-phosphate & $10 \pm 2$ & $5.8 \pm 0.2$ \\
\hline Hypoxanthine & Ribose-5'-phosphate & $3.6 \pm 1$ & $5.4 \pm 1.2$ \\
\hline Guanine & PEE & $0.1 \pm 0.02$ & $1.0 \pm 0.50$ \\
\hline Hypoxanthine & PEE & $0.3 \pm 0.04$ & $3.6 \pm 0.2$ \\
\hline Guanine & PME & $1.6 \pm 0.2$ & $29 \pm 4$ \\
\hline 8-Azaguanine & PME & $3 \pm 0.4$ & $175 \pm 20$ \\
\hline 8-Hydroxyguanine & PME & $1.2 \pm 0.3$ & $68 \pm 6$ \\
\hline 8-Bromoguanine & PME & $10 \pm 4$ & $>400$ \\
\hline Guanine & $(R, S)$-HPMP & $0.6 \pm 0.2$ & $5.9 \pm 0.4$ \\
\hline 8-Bromoguanine & (S)-PMP & $11 \pm 4$ & $>300$ \\
\hline Guanine & Cyclic-(S)-HPMP & $8 \pm 1$ & $90 \pm 10$ \\
\hline Guanine & Cyclic- $(R)$-HPMP & $1 \pm 0.2$ & $19 \pm 5$ \\
\hline
\end{tabular}

${ }^{a}$ Keough et al. [22]

Table 7. Inhibition of PvHGPRT by Acyclic Nucleoside Phosphonates ${ }^{\text {a }}$

\begin{tabular}{|c|c|c|}
\hline Base & Phosphonate & $\mathbf{K}_{\mathbf{i}}(\mu \mathbf{M})$ \\
\hline \hline 8-azaguanine & PEE & $3.3 \pm 0.7$ \\
\hline guanine & 4'-Me-PEE & $6.4 \pm 1.5$ \\
\hline 2-amino-6-bromopurine & PEE & $2.9 \pm 0.8$ \\
\hline
\end{tabular}

${ }^{a}$ Keough et al. [47]

1.6. Comparison of the Amino Acid Sequences between the Human, $P f$ and $P v$ Enzymes and the Location of the Amino Acid Substitutions of PvHGPRT in the Structure of PfHGXPRT

One of the focuses of this review has been the identification of ANPs as antimalarial drug leads. ANPs, depending on the base attached and the chemical characteristics of the linker between the base and the phosphonate group, can be effective inhibitors of the human, $P f$ and $P v$ 6-oxopurine PRTases, though with a range of $K_{i}$ and selectivity values (Tables 6 and 7). Furthermore, differences in catalytic efficiencies for the naturally occurring and exogenous bases between these three enzymes also demonstrate that these enzymes are not identical (Tables $\mathbf{4}$ and 5). The differences in the catalytic properties and inhibition by the ANPs can only be attributed to the changes in the amino acid sequences and three-dimensional structures of the enzymes. A comparison of the overall sequences of the $P f$ and $P v$ 6-oxopurine PRTases shows that they have $77 \%$ amino acid sequence identity Fig. (8). However, when compared with the human enzyme, the identities for PfHGXPRT and for $P v H G P R T$ are lower being $45 \%$ and $39 \%$, respectively. Thus, overall, there is a significant level of sequence variability across the three enzymes. Based on the three-dimensional structures that have been determined for the 6-oxopurine PRTases (Table 8), the binding sites for the purine base, $5^{\prime}$-phosphate, pyrophosphate and $\mathrm{Mg}^{2+}$ have been established. The sequence alignment of the human, $P v$ and $P f$ enzymes Fig. (8) shows that the residues that make up these sites are largely conserved across these three enzymes though there are some subtle differences in sequence when the surrounding areas are considered. The regions of largest sequence difference between the three enzymes are in the $\mathrm{N}$-terminus (residues 14-20), the C-terminus (residues 224-232), residues 96-106 (the mobile loop) and residues 121-124. The amino acid substitutions between the two Plasmodium enzymes occur primarily in the flexible loops Fig. (9) surrounding the active site. The amino acid changes in the core structure are mainly conservative and are not expected to affect the overall fold. It is therefore not immediately obvious as to the molecular basis for the difference in specificities and specific activities of the three enzymes. We discuss this in terms of our knowledge of the 3-D structures of 6-oxopurine PRTases in the section below. 


$1 \quad 10 \quad 20 \quad 30 \quad 40 \quad 50$

Pf MPIPNNPGAGENAFDPVFVNDDDGYDLDSFMIPAHYKKYLTKVLVPNGVIKNRIEKLA

PV $\quad \mathrm{MK} * * * * * * * * * * * \operatorname{LEPIYIK} * * * * * * I * T * L * * D * * * \mathrm{~N} * I * * * * I * * * * \mathrm{~L} * * * * * * * *$

Human -------MATRSPGVVISDDEPGYDLDLFCIPNHYAEDLERVFIPHGLIMDRTERLA

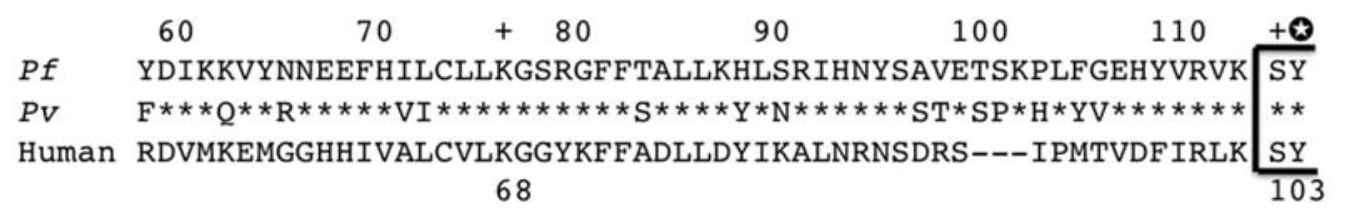

\begin{tabular}{|c|c|c|c|c|c|}
\hline & 120 & $140 \mathrm{Mg}$ & $g^{2+} \#$ & 150 & 170 \\
\hline$P f$ & CNDQSTGTLEIV & S-EDLSCLKGKHVLIVED & DIID & TGKTL & VKFCEYLKKFEIKTVAIAC \\
\hline$P V$ & $* * * * *$ LDRI $* * *$ & $\pi * * * * * * * * \mathrm{D} * * * * * * * *$ & **** & $* * * * *$ & $\mathrm{~L} * * * * \star * * * * * \mathrm{~V} * * \mathrm{I} * * \mathrm{~T} *$ \\
\hline \multirow{3}{*}{ Human } & CNDQSTGDIKVI & JGGDLSTLTGKNVLIVED & DIID & TGKTM & QTLLSLVRQYNPKMVKVAS \\
\hline & Mobile loop & 133 & $5^{\prime}-$ & -site & \\
\hline & 180 & \#\# 200 & + & + & 220 \\
\hline$P f$ & LFIKRTPLWNGFK & KADFVGFSIPDHFVVGYSI & LDYNE & EIFRDLI & DHCCLVNDEGKKKYKATSL- \\
\hline & $\star * \star * * * * * * * * * * *$ & 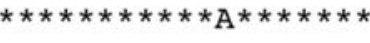 & & * $\mathrm{K}$ ** & $\star \star L * * \star * * * * \star I *$ FRTAPPTA \\
\hline m & LLVKRTPR & KPDFVGFEIPDKFVVGYAL & & EYF & NHVCVISETGKAKYKA---- \\
\hline
\end{tabular}

Fig. (8). Alignment of the amino acid sequences of $P v$ HGPRT, $P f$ HGXPRT and human HGPRT. *indicates identity between the $P f$ and $P v$ enzymes. Red indicates the differences in the sequence between the two parasite enzymes and black those amino acid substitutions which are conservative. Green denotes the residues that interact with the purine base (. The residues which bind to $\mathrm{Mg}^{2+}$ are colored in red while the residues which hold the $\mathrm{PP}_{\mathrm{i}}$ moiety in place are in purple (+). The $5^{\prime}$-phosphate binding residues are designated by a red box and or a white star (tyrosine).

Table 8. Crystal Structures of the 6-Oxopurine PRTases

\begin{tabular}{|c|c|c|}
\hline \multicolumn{3}{|l|}{$\underline{\text { Human }}$} \\
\hline Human HGPRT & $P$ Rib-PP.HPP.Mg ${ }^{2+}[83]$ & 2.7 \\
\hline Human HGPRT & 9-(2-phosphonoethoxyethyl)hypoxanthine [22] & 2.8 \\
\hline Human HGPRT & 9-(2-phosphonoethoxyethyl)guanine [22] & 2.6 \\
\hline Human HGPRT & GMP [56] & 2.5 \\
\hline T. gondii HGPRT & GMP [45] & 1.7 \\
\hline T. gondii HGPRT & IMP [45] & 1.9 \\
\hline T. gondii HGPRT & XMP.PP.. $\mathrm{Mg}^{2+}[46]$ & 1.6 \\
\hline T. gondii HGPRT & 9-deazaguanine, $P$ Rib- $P P . \mathrm{Mg}^{2+}[74]$ & 1.1 \\
\hline T. cruzi HPRT & free $[86]$ & 1.4 \\
\hline T. cruzi HPRT & ternary complex [84] & 1.8 \\
\hline T. cruzi HPRT & IMP [85] & 2.3 \\
\hline
\end{tabular}


(Table 8) contd...

\begin{tabular}{|c|c|c|}
\hline Source & Ligand and Reference & Resolution (̊̊) \\
\hline T. cruzi K68R HPRT & IMP [85] & 2.7 \\
\hline T. cruzi K68R HPRT & 7-hydroxy-pyrazolo[4,3-D]pyrimidine.PRib-PP. $\mathrm{Mg}^{2+}[85]$ & 2.0 \\
\hline G. lamblia GPRT & immGP.PP $\cdot \mathrm{Mg}^{2+}[86]$ & 1.8 \\
\hline G. lamblia GPRT & immGP [86] & 1.8 \\
\hline L. tarentolae HGPRT & GMP [87] & 2.1 \\
\hline \multicolumn{3}{|l|}{$\underline{\text { Bacteria }}$} \\
\hline E. coli XGPRT & free $[88]$ & 1.8 \\
\hline E. coli XGPRT & c $P$ Rib-PP.guanine. $\mathrm{Mg}^{2+}[88]$ & 2.0 \\
\hline E. coli XGPRT & cPRib-PP.xanthine [88] & 2.0 \\
\hline E. coli XGPRT & GMP [89] & 2.0 \\
\hline E. coli HPRT & free $[80]$ & 2.9 \\
\hline E. coli HPRT & IMP [80] & 2.8 \\
\hline E. coli HPRT & GMP [80] & 2.8 \\
\hline
\end{tabular}

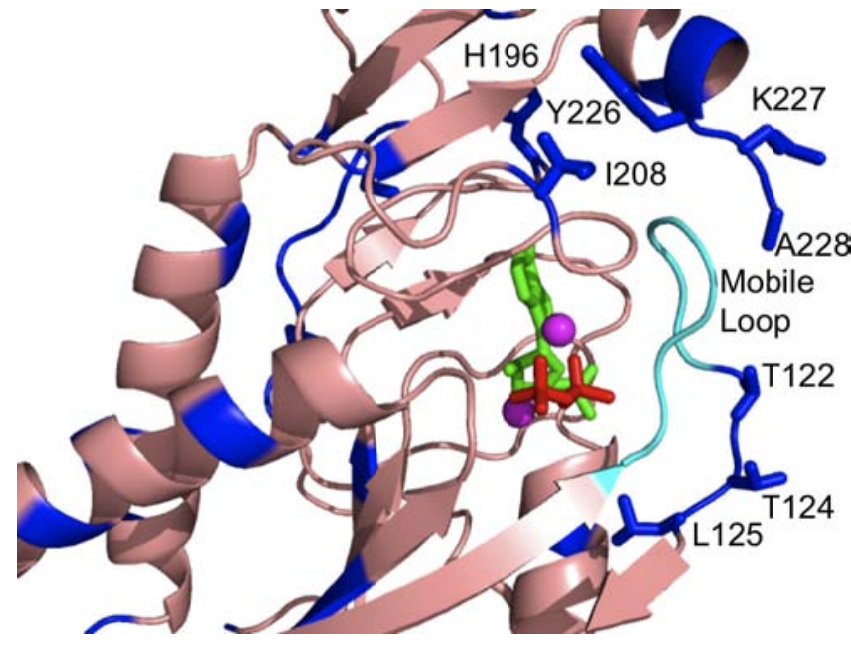

Fig. (9). The active site and surrounding regions of PfHGXPRT. Crystal structure of PfHGXPRT in complex with $\mathrm{Mg}^{2+}$ immucillinHP-5'-phosphate and pyrophosphate. Amino acid residues that differ in the $P f$ and $P v$ enzymes are colored dark blue. Side-chains are displayed as stick models for residues that differ between the two enzymes and that are close to active site. $\mathrm{Mg}^{2+}$ ions are drawn as purple spheres, immucillinHP-5'-phosphate and pyrophosphate as green and red stick models, respectively. The mobile loop is coloured cyan.

\subsection{Crystal Structures of the 6-Oxopurine PRTases}

The crystal structures of a number of the 6-oxopurine PRTases from different organisms have been determined (Table 8). However, only the structures for PfHGXPRT, Giardia lamblia GPRT and human HGPRT have been determined in the presence of inhibitors. All the other structures are either unliganded or in complex with substrates or products. Structures of human HGPRT have been the most widely studied and reveal the movements of the flexible loops that occur during the catalytic cycle (Table 8).

The 6-oxopurine PRTases have a number of structural features that contribute to the binding of the substrates and the products. These include the purine base, 5'-phosphate and pyrophosphate binding sites and the presence of a large flexible (mobile) loop, which closes over the active site during catalysis shielding it from solvent. For human HGPRT, in the unliganded form or in the presence of the mononucleotide product of the reaction, this loop is open and disordered $[55,56]$. However, in complex with the transition state inhibitor, immucillinGP. $\mathrm{Mg}^{2+}$ and $\mathrm{PP}_{\mathrm{i}}$, the loop is firmly closed and ordered and has the structure of two anti-parallel $\beta$-strands [51]. This is a similar conformation as to when immucillinHP. $\mathrm{Mg}^{2+}$ and $\mathrm{PP}_{\mathrm{i}}$ binds to PfHGXPRT [57].

Three structures of human HGPRT in complex with inhibitors have been determined. These are with the ANPs, (S)-9-(3-hydroxy-2-phosphonylmethoxypropyl)guanine, 9(2-phosphonoethoxyethyl)hypoxanthine and 9-(2phosphonoethoxyethyl)guanine [22]. In all of these structures, the mobile loop is mainly random coil but is partially closed over the active site. The movement of this loop is depicted in Fig. (10). The closure of this loop is therefore likely to be an important contributing factor in the binding affinity and selectivity of 6-oxopurine PRTase inhibitors.

The pyrophosphate binding site is a small flexible loop consisting of four amino acids (Table 9). In human HGPRT, replacement of LKGG by LKEG, LKRG, LKGV or LKGR results in a complete absence of activity (Lesch-Nyhan syndrome), emphasising its overall importance. In this region, the $P f$ and $P v$ enzymes differ by one residue (LKGS) compared with the human enzyme. This is, therefore, a potential site for an inhibitor to impart selectivity for the parasite enzymes over the human equivalent. The immucillin $5^{\prime}$ - 

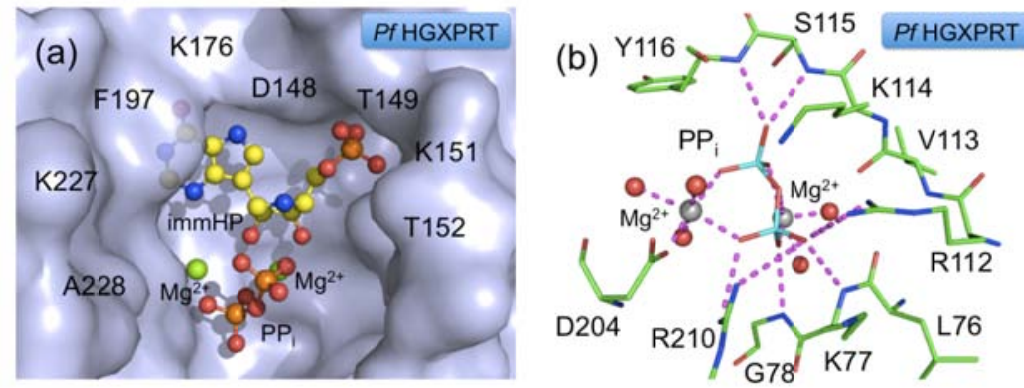

(c)

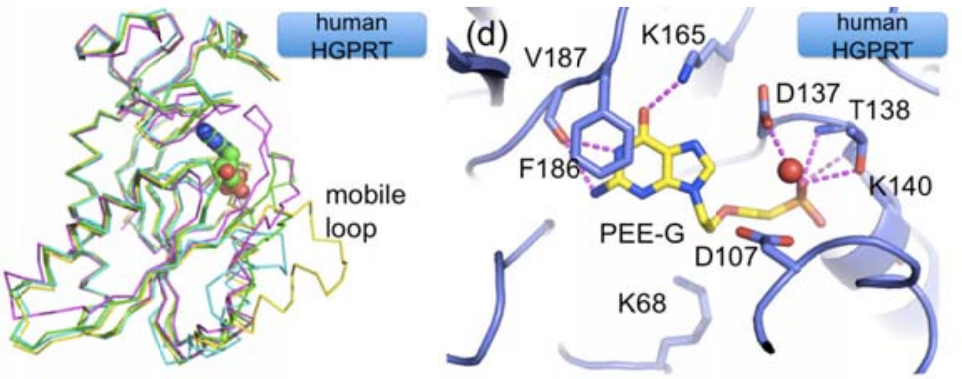

Fig. (10). Crystal structures of PfHGXPRT and human HGPRT. (a) Connolly surface of the active site of PfHGXPRT showing the location of immucillinHP-5'-phosphate, $\mathrm{PP}_{\mathrm{i}}$ and $\mathrm{Mg}^{2+}$. (b) The interactions of $\mathrm{PP}_{\mathrm{i}}$ and $\mathrm{Mg}^{2+}$ with active site residues in PfHGXPRT. (c) The subunit structure of human HGPRT showing the movement of the large (mobile) loop which occurs during catalysis. (d) The interactions between the ANP inhibitor, PEEG, and active site residues in human HGPRT.

Table 9. The Amino Acid Sequence in the Pyrophosphate Binding Loop in Different 6-Oxopurine PRTases

\begin{tabular}{|c|c|c|}
\hline Human & LKGG & 25 \\
\hline$P f, P v, T$, gondii & LKGS & $\mathrm{NK}^{\mathrm{a}}$ \\
\hline T. foetus & LTGA & 165 \\
\hline G. lamblia & LTGA & 424 \\
\hline
\end{tabular}

${ }^{\mathrm{a}} \mathrm{NK}=$ not known

phosphates only bind in the presence of pyrophosphate and magnesium ions. Thus, occupancy of the pyrophosphate binding site appears to be another contributing factor leading to an increased binding affinity of the immucillin $5^{\prime}$ phosphates to these enzymes.

The 5'-phosphate binding pocket Fig. (10), Table 9; TGKTL for $P f$ and $P v$ ), is a highly conserved region of the 6-oxopurine PRTases. In human HGPRT, this region, like the pyrophosphate and the large mobile loop is also flexible. In the free human HGPRT crystal structure, the distance between T138 and T141 is only $4.3 \AA$ [55]. This distance expands to $7.8 \AA$ when the $5^{\prime}$-phosphate group is bound, thereby preparing the active site for the purine base to enter [56]. This binding pocket anchors the phosphate group of the immucillin $5^{\prime}$-phosphates and the phosphonate moiety of the ANPs in position contributing to their affinity.
The residues involved in binding the purine base are D148, K176, F197 and V198 in PfHGXPRT Fig. (10). These are conserved in the human and $P v$ enzymes. D148 binds to the N7 nitrogen, K176 binds to the 6-oxo group and confers specificity for the 6-oxopurines over the 6-aminopurines, while F197 forms a pi bond with the purine ring and the carbonyl oxygen of V198 can form hydrogen bond(s) to the N1 nitrogen and the R substituent Fig. (10) of the C2 carbon of the purine ring. The structural contribution to the differences in affinity for the purine bases between the human and $P f$ and $P v$ enzymes is unclear. This can be attributed to the present lack of structures of the parasite enzymes. The only direct comparison between the $P f$ and human enzymes are the complexes with the immucillin $5^{\prime}$-phosphates. In these structures, the amino acid side chains and the backbone atoms which place the base in position are in completely conserved locations. PfHGXPRT was solved only with its preferred base, Hx, attached to the immucillin $5^{\prime}$-phosphate 
(Tables $\mathbf{3}$ and $\mathbf{8}$ ) while human HGPRT was also only solved with its preferred base, guanine, attached. If structures were available with alternate bases, this would aid in the understanding of the purine base specificity for these enzymes.

\subsection{Inhibitors of the 6-Oxopurine PRTases from other Protozoan Parasites}

There are a number of other protozoan parasites that infect humans and animals leading to severely debilitating and potentially life-threatening diseases. Amongst the most serious and widespread of these parasites are Leishmania donovani, Giardia lamblia, Trypanosoma cruzi, Toxoplasma gondi and Tritrichomonas foetus. The first four of these result in infection to humans while the last of these is prevalent in cattle and therefore pose a serious risk to the meat and dairy industries. While there are differences in the metabolism between these parasites, they share a commonality in that they are all auxotrophic for the purine ring. Thus, the 6oxopurine PRTases have been studied in these parasites with a view to developing chemotherapeutic agents that targets these enzymes.

Through broad screening approaches, using both chemical and computational libraries, a number of molecules have been discovered as inhibitors of protozoan parasite 6oxopurine PRTases. These have targeted the enzymes from T. cruzi, T. foetus and G. lamblia.

Table 10. Inhibitors of T. cruzi $i^{a}$

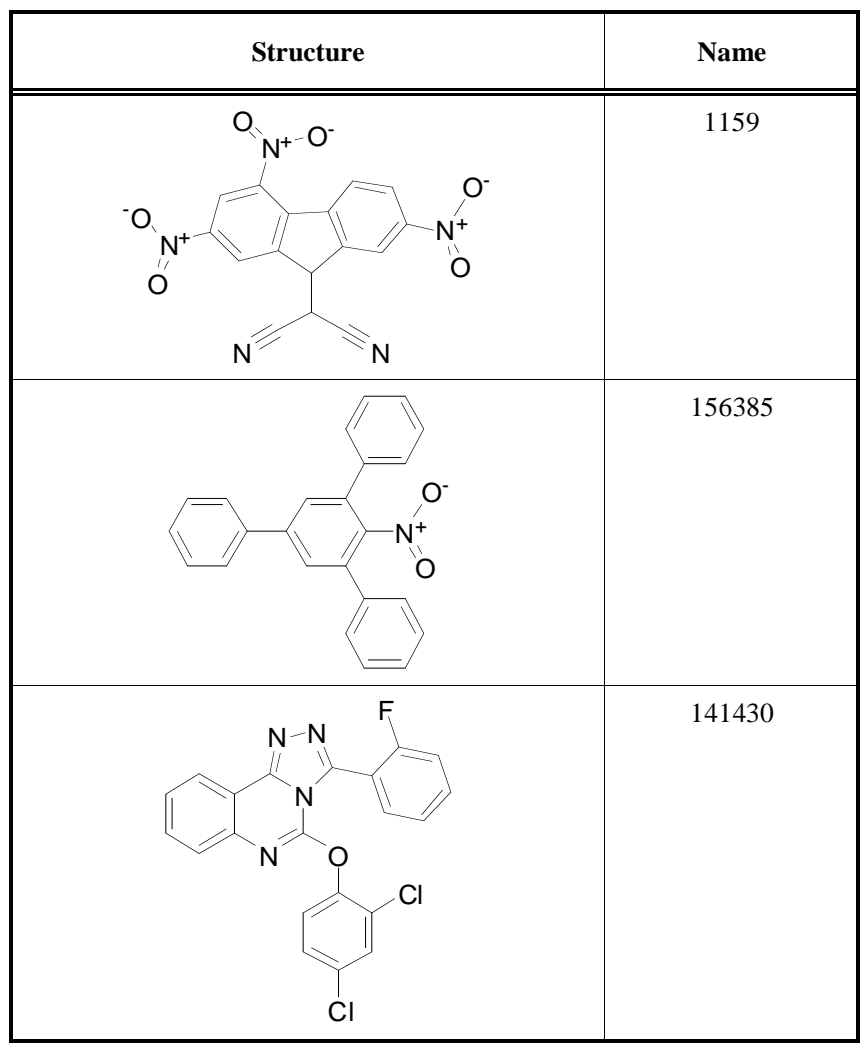

${ }^{\mathrm{a}}$ Freymann et al. [58]

Four compounds as potential inhibitors (Tables $\mathbf{1 0}$ and 11) of $T$. cruzi HPRT were identified using a modified version of the program, DOCK [58]. These results came from the in silico screening of over 34 million compounds. Their
$\mathrm{K}_{\mathrm{i}}$ values for the enzymes from $T$. cruzi, human and $S$. typhimurium were determined (Table 11), and for T. cruzi HPRT, these values ranged from $0.5 \mu \mathrm{M}$ to $11.8 \mu \mathrm{M}$ and the selectivity over the human counterpart ranged between 2.5 32. Three of these compounds (Compound numbers 1159 , 141430 and 156385) were also found to inhibit the growth of the parasite in infected mouse macrophages. The addition of increased levels of $\mathrm{Hx}$ to the media (up to $300 \mu \mathrm{M}$ from 2.5 $\mu \mathrm{M})$ reversed this inhibition, strongly suggesting that the target was indeed HPRT. The chrysene compound (32980), though a good inhibitor of $T$. cruzi HPRT with a $\mathrm{K}_{\mathrm{i}}$ value of $0.5 \pm 0.06 \mu \mathrm{M}$, was the only compound that did not inhibit parasite growth. This was a disappointing finding as it was selective for the parasite enzyme, having a $\mathrm{K}_{\mathrm{i}}$ value of $16 \pm$ 9.2 $\mu \mathrm{M}$ (32-fold difference in selectivity). Subsequently, chrysene derivatives were further investigated as potential anti-parasitic drugs. These compounds are very hydrophobic and, though exhibiting $\mathrm{K}_{\mathrm{i}}$ values between 0.5-9 $\mu \mathrm{M}$ (Table 12), they also did not inhibit the growth of the parasite [59]. These molecules contain a cluster of four aromatic rings (Table 12). It is likely that a portion of these would occupy or partially occupy the purine binding site. The aromatic amino acid that covers the purine binding site (F197 in PfHGXPRT; F164 in T. cruzi HPRT) would potentially form a pi-stacking arrangement with the aromatic rings from these inhibitors. Unfortunately, these molecules have proved ineffective in vivo. The reason for their failure is attributed to their inability to be transported through the plasma membrane, even though they appear to be quite hydrophobic [59]. Nonetheless, a $K_{i}$ value of $0.5 \mu \mathrm{M}$ for the best of these inhibitors for T. cruzi HPRT is encouraging and suggests that derivatives of this class could be useful as drug leads if a delivery system can be developed.

Table 11. Kinetic Inhibition Constants for Lead Inhibitors of T. cruzi HPRT ${ }^{\mathrm{a}}$

\begin{tabular}{|c|c|c|c|}
\hline \multirow{2}{*}{ Inhibitor } & \multicolumn{3}{|c|}{$\mathbf{K}_{\mathrm{i}}(\mu \mathrm{M})$} \\
\cline { 2 - 4 } & $\boldsymbol{T}$. cruzi & human & S. typhimurium \\
\hline \hline 1159 & $2.2 \pm 0.2$ & $5.4 \pm 1.1$ & - \\
\hline 32980 & $0.5 \pm 0.06$ & $16.0 \pm 9.2$ & $>>25$ \\
\hline 141430 & $11.8 \pm 0.8$ & $28.8 \pm 4.7$ & $48.1 \pm 1.8$ \\
\hline 156385 & $2.0 \pm 0.2$ & $10.9 \pm 1.6$ & $13.9 \pm 0.7$ \\
\hline
\end{tabular}

${ }^{a}$ Freymann et al. [58]

The compound 4-[N-(3,4-dichlorophenyl)carbamoyl] phthalic anhydride called TF1; Fig. (11) was identified by computational docking as a potential inhibitor for $T$. foetus HGXPRT [60]. Kinetic studies confirmed that TF1 is a competitive inhibitor of guanine and GMP with $\mathrm{K}_{\mathrm{i}}$ values of 13 $\mu \mathrm{M}$ and $10 \mu \mathrm{M}$, respectively. TF1 does not inhibit human HGPRT even at concentrations of $1 \mathrm{mM}$, so is highly selective for the parasite enzyme. TF1 inhibited the growth of $T$. foetus in culture with an $\mathrm{EC}_{50}$ of $40 \mu \mathrm{M}$ [61]. This corresponded to a decrease in the amount of exogenous guanine incorporated into the parasite's nucleic acids which could be reversed by supplementation of the media with excess hy- 
Table 12. Chrysene-derivatives as inhibitors of T. cruzi HPRT $^{\text {a }}$

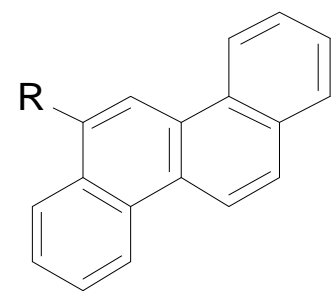

\begin{tabular}{|c|c|}
\hline Structure of the R group & $\mathbf{K}_{\mathbf{i}}(\mu \mathbf{M})$ \\
\hline \hline $\mathrm{H}$ & $8.9 \pm 0.2$ \\
\hline $\mathrm{H}$ & $2.8 \pm 0.2$ \\
\hline & \\
\hline & \\
\hline
\end{tabular}

${ }^{a}$ Medrano et al. [59]

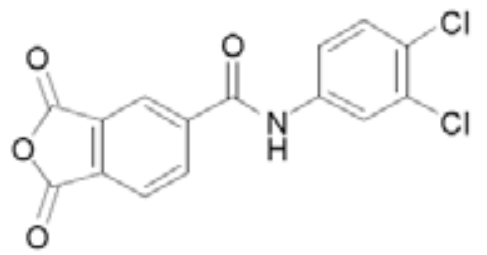

Fig. (11). Structure of 4-[N-(3,4-dichlorophenyl)carbamoyl] phthalic anhydride (TF1).

poxanthine or guanine [60]. Thus, these data provide further evidence that compounds which block the purine salvage pathway is detrimental to the life cycle of such protozoan parasites. Based on this structure, a virtual library of substituted 4-phthalimidocarboxanilines was screened. This led to the development of TF2 [( $4^{\prime}$-phthalimido)carboxamido-3-(4bromobenzyloxy)benzene] Fig. (12) [61]. The effect of these substitutions was to reduce the $\mathrm{K}_{\mathrm{i}}$ with respect to guanine to $0.49 \mu \mathrm{M}$ (26-fold lower). Though this compound is a good inhibitor of the parasite enzyme, the selectivity in favour of this enzyme compared to human HGPRT was reduced to 30. This compound also arrested parasitemia with an $\mathrm{ED}_{50}$ of 2.8 $\mu \mathrm{M}$. This reduction in the $\mathrm{ED}_{50}$ value compared with $\mathrm{TF} 1$ (14-fold) is consistent with the tighter binding to T. foetus HGPRT. As with TF1, the effect on the growth of the parasite could be reversed by the addition of exogenous Hx. TF2 is not a competitive inhibitor with $P$ Rib- $P P$ as predicted from the docking studies which argued for non-overlapping binding sites with the substrate.

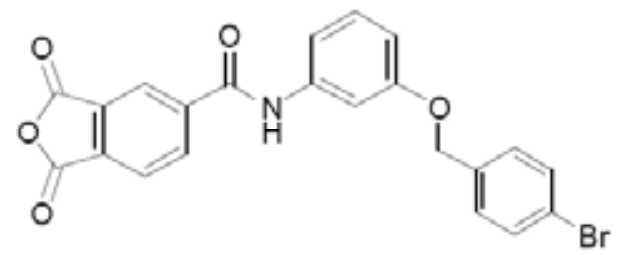

Fig. (12). Structure of [(4'-phthalimido)carboxamido-3-(4bromobenzyloxy)benzene] (TF2).

A structural library using derivatives based on phthalimide chemistry was screened against $G$. lamblia GPRT [62]. From more than 300 molecules tested, two were found to inhibit $G$. lamblia GPRT with $\mathrm{K}_{\mathrm{i}}$ values around 24 $\mu \mathrm{M}$ Fig. (13). However, these compounds were not highly selective for the parasite enzyme compared with human HGPRT with $\mathrm{IC}_{50}$ ratios between the two enzymes of only 1to 2-fold.
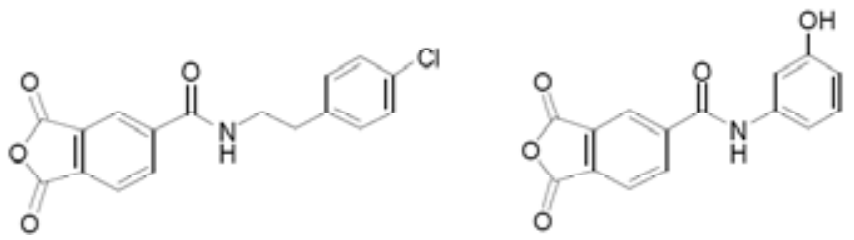

Fig. (13). Structures of inhibitors of G. lamblia GPRT.

Bisphosphonates which are analogs of the pyrophosphate product of the reaction have been found to inhibit $T$. cruzi HPRT [63]. Their structures are given in Fig. (14). These compounds are competitive inhibitors of pyrophosphate with $\mathrm{K}_{\mathrm{i}}$ values for $T$. cruzi HPRT of $188.6 \pm 11.8 \mu \mathrm{M}$ (ALN), $126.0 \pm 5.0 \mu \mathrm{M}(\mathrm{OPD}), 50.6 \pm 3.7 \mu \mathrm{M}(\mathrm{PAM})$ and $23.2 \pm 2.3$ $\mu \mathrm{M}$ (RIS). These compounds could potentially inhibit many other enzymes involved in organic and pyrophosphate reactions such as farnesyl-pyrophosphate synthase, squalene synthase or proton-pumping pyrophosphatases. Thus their mode of action at the cellular level is unclear. However, these molecules do appear to be capable of inhibiting the 6-oxopurine PRTases by blocking the pyrophosphate binding site.<smiles>[R]C(O)(P(=O)(O)O)P(=O)(O)O</smiles>

Fig. (14). Bisphosphonates as inhibitors of $T$. cruzi HPRT. $\mathrm{R}=\left(\mathrm{CH}_{2}\right)_{3} \mathrm{NH}_{3}{ }^{+}(\mathrm{ACN}), \quad\left(\mathrm{CH}_{2}\right)_{2} \mathrm{NH}\left(\mathrm{CH}_{3}\right)_{2}{ }^{+}(\mathrm{OPD}), \quad\left(\mathrm{CH}_{2}\right)_{2} \mathrm{NH}_{3}{ }^{+}$ (PAM) and $\mathrm{CH}_{2}$ (3-pyridinyl) ${ }^{+}$(RIS).

A comparison of the sequences of $P f, P v, T$. cruzi, $T$. gondii, T. foetus and L. donavani 6-oxopurine PRTases shows that, although they can have overall identities as low as $22 \%$, the residues that make up their active site (i.e. those highlighted in Fig. (9) are almost $100 \%$ conserved across these six enzymes. The only variations that exist across these enzymes are conserved differences at the $5^{\prime}$-phosphate binding site (i.e. residue 150 (PfHGXPRT numbering) can be $\mathrm{S} / \mathrm{T}, 151 \mathrm{~A} / \mathrm{G}$, and $152 \mathrm{I} / \mathrm{K} / \mathrm{L} / \mathrm{F})$ and F197, the aromatic residue that covers the purine binding pocket which is tryptophan in the $T$. gondii enzyme but phenylalanine in all of the 
others. It is therefore proposed that drugs directed toward the Plasmodium 6-oxopurine PRTases should also be leads in drug discovery for other protozoan parasitic diseases and vice-versa. Furthermore, this review clearly demonstrates that potent inhibitors of parasitic 6-oxopurine PRTases are not necessarily inhibitors of the human enzyme and, thus, design of drugs targeted specifically to the enzymes from protozoan parasites is feasible.

\section{CONCLUSION}

Due to the widespread emergence of drug resistant strains of the malarial parasites, it is imperative that new drugs are discovered and become commercially available or can be donated to developing countries through charitable organizations such as the Bill and Melinda Gates Foundation or the World Health Organization (WHO). This review establishes the purine salvage pathway as a drug target because it is essential for the survival and replication of the parasite. Drugs that target the 6-oxopurine PRTase alone should be very effective, but a cocktail that can successfully inhibit ADA and PNP [64] (two other important enzymes in the production of the nucleoside monophosphates) should make it virtually impossible for the parasite to mutate and survive. ANPs are particularly attractive lead compounds because not only are they selective for the Plasmodium enzymes over the human counterpart but they have been found to exhibit excellent pharmacokinetic properties and, because of the carbon-phosphorous bond, are stable within the cell.

\section{ACKNOWLEDGEMENTS}

This work is supported by grant number 569703 from the National Health and Medical Research Council, Australia, and project AVOZ40550506 of the Institute of Organic Chemistry and Biochemistry was supported by Centre for New Antivirals and Antineoplastics, Czeck Republic (1M0508).

\section{ABBREVIATIONS}

\begin{tabular}{|c|c|c|}
\hline$P f$ & $=$ & Plasmodium falciparum \\
\hline$P v$ & $=$ & Plasmodium vivax \\
\hline HGPRT & $=$ & $\begin{array}{l}\text { hypoxanthine-guanine phosphoribosyltrans } \\
\text { ferase }\end{array}$ \\
\hline HGXPRT & $=$ & $\begin{array}{l}\text { hypoxanthine-guanine-xanthine phosphori- } \\
\text { bosyltransferase }\end{array}$ \\
\hline PRTase & $=$ & phosphoribosyltransferase \\
\hline$P$ Rib- $P P$ & $=$ & 5-phospho- $\alpha$-D-ribosyl-1-pyrophosphate \\
\hline ANP & $=$ & acyclic nucleoside phosphonate \\
\hline immGP & $=$ & $\begin{array}{l}(1 S) \text {-1-(9-deazaguanin-9-yl)-1,4-dideoxy- } \\
\text { 1,4-imino-D-ribitol 5-phosphate }\end{array}$ \\
\hline immHP & $=$ & $\begin{array}{l}(1 S)-1-(9-d e a z a h y p o x a n t h i n-9-y l)-1,4- \\
\text { dideoxy-1,4-imino-D-ribitol 5-phosphate }\end{array}$ \\
\hline PEEG & $=$ & 9-(2-phosphonoethoxyethyl)guanine \\
\hline IMP & $=$ & inosine $5^{\prime}$-monophosphate \\
\hline $\mathrm{Hx}$ & $=$ & hypoxanthine \\
\hline
\end{tabular}

PNP $=$ purine nucleoside phosphorylase

ADA $=$ adenosine deaminase

\section{REFERENCES}

[1] Mendes, A. M.; Schlegelmilch, T.; Cohuet, A.; Awono-Ambene, P.; De Iorio, M.; Fontenille, D.; Morlais, I.; Christophides, G. K.; Kafatos, F. C.; Vlachou, D. Conserved mosquito/parasite interactions affect development of Plasmodium falciparum in Africa. PLoS Pathog., 2008, 4(5), e1000069.

[2] Marechal, E.; Azzouz, N.; de Macedo, C. S.; Block, M. A.; Feagin, J. E.; Schwarz, R. T.; Joyard, J. Synthesis of chloroplast galactolipids in apicomplexan parasites. Eukaryotic cell, 2002, 1(4), 653-656.

[3] Marechal, E.; Cesbron-Delauw, M. F. The apicoplast: a new member of the plastid family. Trends Plant Sci., 2001, 6(5), 200-205.

[4] Chin, W.; Contacos, P. G.; Coatney, G. R.; Kimball, H. R. A naturally acquired quotidian-type malaria in man transferable to monkeys. Science, 1965, 149(3686), 865.

[5] Cox-Singh, J.; Singh, B. Knowlesi malaria: newly emergent and of public health importance? Trends Parasitol., 2008, 24(9), 406-410.

[6] Jongwutiwes, S.; Putaporntip, C.; Iwasaki, T.; Sata, T.; Kanbara, H. Naturally acquired Plasmodium knowlesi malaria in human, Thailand. Emerging Infect. Dis., 2004, 10(12), 2211-2213.

[7] Mueller, I.; Galinski, M. R.; Baird, J. K.; Carlton, J. M.; Kochar, D. K.; Alonso, P. L.; del Portillo, H. A. Key gaps in the knowledge of Plasmodium vivax, a neglected human malaria parasite. Lancet Infect. Dis., 2009, 9(9), 555-566.

[8] Snow, R. W.; Guerra, C. A.; Noor, A. M.; Myint, H. Y.; Hay, S. I. The global distribution of clinical episodes of Plasmodium falciparum malaria. Nature, 2005, 434(7030), 214-217.

[9] Baird, J. K. Resistance to therapies for infection by Plasmodium vivax. Clin. Microbiol. Rev., 2009, $22(3), 508-534$.

[10] Killeen, G. F.; Fillinger, U.; Kiche, I.; Gouagna, L. C.; Knols, B. G. J. Eradication of Anopheles gambiae from Brazil: Lessons for malaria control in Africa? Lancet Infect. Dis., 2002, 2 (10), 618-627.

[11] Ito, J.; Ghosh, A.; Moreira, L. A.; Wimmer, E. A.; Jacobs-Lorena, M. Transgenic anopheline mosquitoes impaired in transmission of a malaria parasite. Nature, 2002, 417 (6887), 452-455.

[12] Matuschewski, K. Vaccine development against malaria. Curr. Opin. Immunol., 2006, 18(4), 449-457.

[13] McCarthy, J. S.; Good, M. F. Whole parasite blood stage malaria vaccines: A convergence of evidence. Hum. Vaccines, 2010, 6(1), 114-123.

[14] Herrera, S.; Corradin, G.; Arevalo-Herrera, M. An update on the search for a Plasmodium vivax vaccine. Trends Parasitol., 2007, 23(3), 122-128.

[15] Greenwood, D. The quinine connection. J. Antimicrob. Chemother., 1992, 30(4), 417-427.

[16] Kaur, K.; Jain, M.; Reddy, R. P.; Jain, R. Quinolines and structurally related heterocycles as antimalarials. Eur. J. Med. Chem., 2010, 45, 3245-3264.

[17] Martin, R. E.; Marchetti, R. V.; Cowan, A. I.; Howitt, S. M.; Broer, S.; Kirk, K. Chloroquine transport via the malaria parasite's chloroquine resistance transporter. Science, 2009, 325(5948), 1680-1682.

[18] Carlton, J. M.; Adams, J. H.; Silva, J. C.; Bidwell, S. L.; Lorenzi, H.; Caler, E.; Crabtree, J.; Angiuoli, S. V.; Merino, E. F.; Amedeo, P.; Cheng, Q.; Coulson, R. M.; Crabb, B. S.; Del Portillo, H. A.; Essien, K.; Feldblyum, T. V.; Fernandez-Becerra, C.; Gilson, P. R.; Gueye, A. H.; Guo, X.; Kang'a, S.; Kooij, T. W.; Korsinczky, M.; Meyer, E. V.; Nene, V.; Paulsen, I.; White, O.; Ralph, S. A.; Ren, Q.; Sargeant, T. J.; Salzberg, S. L.; Stoeckert, C. J.; Sullivan, S. A.; Yamamoto, M. M.; Hoffman, S. L.; Wortman, J. R.; Gardner, M. J.; Galinski, M. R.; Barnwell, J. W.; Fraser-Liggett, C. M. Comparative genomics of the neglected human malaria parasite Plasmodium vivax. Nature, 2008, 455(7214), 757-763.

[19] Gardner, M. J.; Hall, N.; Fung, E.; White, O.; Berriman, M.; Hyman, R. W.; Carlton, J. M.; Pain, A.; Nelson, K. E.; Bowman, S.; Paulsen, I. T.; James, K.; Eisen, J. A.; Rutherford, K.; Salzberg, S. L.; Craig, A.; Kyes, S.; Chan, M. S.; Nene, V.; Shallom, S. J.; Suh, B.; Peterson, J.; Angiuoli, S.; Pertea, M.; Allen, J.; Selengut, J.; Haft, D.; Mather, M. W.; Vaidya, A. B.; Martin, D. M. A.; Fairlamb, A. H.; Fraunholz, M. J.; Roos, D. S.; Ralph, S. A.; McFadden, G. I.; Cummings, L. M.; Subramanian, G. M.; Mungall, C.; Venter, J. C.; Carucci, D. J.; Hoffman, S. L.; Newbold, C.; Davis, 
R. W.; Fraser, C. M.; Barrell, B. Genome sequence of the human malaria parasite Plasmodium falciparum. Nature, 2002, 419(6906), 498-511.

[20] Guiguemde, W. A.; Shelat, A. A.; Bouck, D.; Duffy, S.; Crowther, G. J.; Davis, P. H.; Smithson, D. C.; Connelly, M.; Clark, J.; Zhu, F. Y.; Jimenez-Diaz, M. B.; Martinez, M. S.; Wilson, E. B.; Tripathi, A. K.; Gut, J.; Sharlow, E. R.; Bathurst, I.; El Mazouni, F.; Fowble, J. W.; Forquer, I.; McGinley, P. L.; Castro, S.; AnguloBarturen, I.; Ferrer, S.; Rosenthal, P. J.; DeRisi, J. L.; Sullivan, D. J.; Lazo, J. S.; Roos, D. S.; Riscoe, M. K.; Phillips, M. A.; Rathod, P. K.; Van Voorhis, W. C.; Avery, V. M.; Guy, R. K. Chemical genetics of Plasmodium falciparum. Nature, 2010, 465(7296), 311315 .

[21] Galinski, M. R.; Barnwell, J. W. Plasmodium vivax: who cares? Malar. J., 2008, 7 (Suppl 1), S9.

[22] Gayathri, P.; Balaram, H.; Murthy, M. Structural biology of plasmodial proteins. Curr. Opin. Struct. Biol., 2007, 17(6), 744-754.

[23] Duckworth, M.; Menard, A.; Megraud, F.; Mendz, G. L. Bioinformatic analysis of Helicobacter pylori XGPRTase: A potential therapeutic target. Helicobacter, 2006, 11(4), 287-295.

[24] Dawson, P. A.; Gordon, R. B.; Keough, D. T.; Emmerson, B. T. Normal HPRT coding region in a male with gout due to HPRT deficiency. Mol. Gen. Metab., 2005, 85(1), 78-80.

[25] Zolg, J. W.; Macleod, A. J.; Dickson, I. H.; Scaife, J. G. Plasmodium falciparum : Modifications of the in vitro culture conditions improving parasitic yields. J. Parasitol., 1982, 68(6), 1072-1080.

[26] Berman, P. A.; Human, L.; Freese, J. A. Xanthine oxidase inhibits growth of Plasmodium falciparum in human erythrocytes in vitro. J. Clin. Invest., 1991, 88(6), 1848-1855.

[27] Gero, A. M.; Wood, A. M. New nucleoside transport pathways induced in the host erythrocyte membrane of malaria and babesia infected cells. Purine Pyrimidine Metabol. Man VII, Pt A, 1991, 309, 169-172.

[28] Riegelhaupt, P. M.; Cassera, M. B.; Frohlich, R. F. G.; Hazleton, K. Z.; Hefter, J. J.; Schramm, V. L.; Akabas, M. H. Transport of purines and purine salvage pathway inhibitors by the Plasmodium falciparum equilibrative nucleoside transporter PfENT1. Mol. Biochem. Parasitol., 2010, 169(1), 40-49.

[29] El Bissati, K.; Zufferey, R.; Witola, W. H.; Carter, N. S.; Ullman, B.; Ben Mamoun, C. The plasma membrane permease PfNT1 is essential for purine salvage in the human malaria parasite Plasmodium falciparum. Proc. Natl. Acad. Sci. USA, 2006, 103 (24), 92869291.

[30] El Bissati, K.; Downie, M. J.; Kim, S. K.; Horowitz, M.; Carter, N.; Ullman, B.; Ben Mamoun, C. Genetic evidence for the essential role of PfNT1 in the transport and utilization of xanthine, guanine, guanosine and adenine by Plasmodium falciparum. Mol. Biochem. Parasitol., 2008, 161(2), 130-139.

[31] Carter, N. S.; Ben Mamoun, C.; Liu, W.; Silva, E. O.; Landfear, S. M.; Goldberg, D. E.; Ullman, B. Isolation and functional characterization of the PfNT1 nucleoside transporter gene from Plasmodium falciparum. J. Biol. Chem., 2000, 275(14), 10683-10691.

[32] Martin, R. E.; Henry, R. I.; Abbey, J. L.; Clements, J. D.; Kirk, K. The 'permeome' of the malaria parasite: an overview of the membrane transport proteins of Plasmodium falciparum. Genom. Biol., 2005, 6(3), R26.

[33] Ting, L. M.; Shi, W. X.; Lewandowicz, A.; Singh, V.; Mwakingwe, A.; Birck, M. R.; Ringia, E. A. T.; Bench, G.; Madrid, D. C.; Tyler, P. C.; Evans, G. B.; Furneaux, R. H.; Schramm, V. L.; Kim, K. Targeting a novel Plasmodium falciparum purine recycling pathway with specific immucillins. J. Biol. Chem., 2005, 280(10), 9547-9554.

[34] Reyes, P.; Rathod, P. K.; Sanchez, D. J.; Mrema, J. E. K.; Rieckmann, K. H.; Heidrich, H. G. Enzymes of purine and pyrimidine metabolism from the human malaria, Plasmodium falciparum. Mol. Biochem. Parasitol., 1982, 5(5), 275-290.

[35] Cassera, M. B.; Hazleton, K. Z.; Riegelhaupt, P. M.; Merino, E. F.; Luo, M. K.; Akabas, M. H.; Schramm, V. L. Erythrocytic adenosine monophosphate as an alternative purine source in Plasmodium falciparum. J. Biol. Chem., 2008, 283(47), 32889-32899.

[36] Musick, W. D. L. Structural features of the phosphoribosyltransferases and their relationship to the human deficiency disorders of purine and pyrimidine metabolism. Crit. Rev. Biochem., 1981, 11(1), 1-34.
[37] Krenitsky, T. A.; Papaioannou, R.; Elion, G. B. Human hypoxanthine phosphoribosyltransferase. I. Purification, properties, and specificity. J. Biol. Chem., 1969, 244(5), 1263-1270.

[38] Xu, Y.; Eads, J.; Sacchettini, J. C.; Grubmeyer, C. Kinetic mechanism of human hypoxanthine-guanine phosphoribosyltransferase: Rapid phosphoribosyl transfer chemistry. Biochemistry, 1997, 36(12), 3700-3712.

[39] Munagala, N. R.; Wang, C. C. Altering the purine specificity of hypoxanthine-guanine-xanthine phosphoribosyltransferase from Tritrichomonas foetus by structure-based point mutations in the enzyme protein. Biochemistry, 1998, 37(47), 16612-16619.

[40] Jardim, A.; Bergeson, S. E.; Shih, S.; Carter, N.; Lucas, R. W.; Merlin, G.; Myler, P. J.; Stuart, K.; Ullman, B. Xanthine phosphoribosyltransferase from Leishmania donovani. Molecular cloning, biochemical characterization, and genetic analysis. J. Biol. Chem., 1999, 274 (48), 34403-34410.

[41] Yuan, L.; Craig, S. P., 3rd; McKerrow, J. H.; Wang, C. C., Steadystate kinetics of the schistosomal hypoxanthine-guanine phosphoribosyltransferase. Biochemistry, 1992, 31(3), 806-810.

[42] Wenck, M. A.; Medrano, F. J.; Eakin, A. E.; Craig, S. P. r., Steadystate kinetics of the hypoxanthine phosphoribosyltransferase from Trypanosoma cruzi. Biochim. Biophys. Acta, 2004, 1700(1), 11-18.

[43] Bhatia, M. B.; Vinitsky, A.; Grubmeyer, C., Kinetic mechanism of orotate phosphoribosyltransferase from Salmonella typhimurium. Biochemistry, 1990, 29(46), 10480-10487.

[44] Krahn, J. M.; Kim, J. H.; Burns, M. R.; Parry, R. J.; Zalkin, H.; Smith, J. L. Coupled formation of an amidotransferase interdomain ammonia channel and a phosphoribosyltransferase active site. Biochemistry, 1997, 36(37), 11061-11068.

[45] Heroux, A.; White, E. L.; Ross, L. J.; Borhani, D. W. Crystal structures of the Toxoplasma gondii hypoxanthine-guanine phosphoribosyltransferase-GMP and -IMP complexes: Comparison of purine binding interactions with the XMP complex. Biochemistry, 1999, 38(44), 14485-14494.

[46] Heroux, A.; White, E. L.; Ross, L. J.; Davis, R. L.; Borhani, D. W. Crystal structure of Toxoplasma gondii hypoxanthine-guanine phosphoribosyltransferase with XMP, pyrophosphate, and two $\mathrm{Mg}^{2+}$ ions bound: Insights into the catalytic mechanism. Biochemistry, 1999, 38(44), 14495-14506.

[47] Keough, D. T.; Hocková, D.; Krečmerová, M.; Česnek, M.; Holý, A.; Naesens, L.; Brereton, I. M.; Winzor, D. J.; de Jersey, J.; Guddat, L. W. Plasmodium vivax hypoxanthine-guanine phosphoribosyltransferase: A target for anti-malarial chemotherapy. Mol. Biochem. Parasitol., 2010, 173(2),165-169

[48] Erb, N.; Harms, D. O.; Janka-Schaub, G. Pharmacokinetics and metabolism of thiopurines in children with acute lymphoblastic leukemia receiving 6-thioguanine versus 6-mercaptopurine. Cancer Chemother. Pharmacol., 1998, 42(4), 266-272.

[49] Keough, D. T.; Skinner-Adams, T.; Jones, M. K.; Ng, A. L.; Brereton, I. M.; Guddat, L. W.; de Jersey, J. Lead compounds for antimalarial chemotherapy: Purine base analogs discriminate between human and $P$. falciparum 6-oxopurine phosphoribosyltransferases. J. Med. Chem., 2006, 49(25), 7479-7486.

[50] Li, C. M.; Tyler, P. C.; Furneaux, R. H.; Kicska, G.; Xu, Y. M.; Grubmeyer, C.; Girvin, M. E.; Schramm, V. L. Transition-state analogs as inhibitors of human and malarial hypoxanthine-guanine phosphoribosyltransferases. Nat. Struct. Biol., 1999, 6(6), 582-587.

[51] Shi, W.; Li, C. M.; Tyler, P. C.; Furneaux, R. H.; Grubmeyer, C.; Schramm, V. L.; Almo, S. C. The $2.0 \AA$ structure of human hypoxanthine-guanine phosphoribosyltransferase in complex with a transition-state analog inhibitor. Nat. Struct. Biol., 1999, 6(6), 588593.

[52] Holý, A., Phosphonomethoxyalkyl analogs of nucleotides. Curr. Pharm. Des., 2003, 9 (31), 2567-2592.

[53] De Clercq, E.; Holý, A. Acyclic nucleoside phosphonates: A key class of antiviral drugs. Nat. Rev. Drug Discov., 2005, 4(11), 928940 .

[54] Smeijsters, L. J.; Franssen, F. F.; Naesens, L.; de Vries, E.; Holý, A.; Balzarini, J.; de Clercq, E.; Overdulve, J. P. Inhibition of the in vitro growth of Plasmodium falciparum by acyclic nucleoside phosphonates. Int. J. Antimicrob. Agents, 1999, 12(1), 53-61.

[55] Keough, D. T.; Brereton, I. M.; de Jersey, J.; Guddat, L. W. The crystal structure of free human hypoxanthine guanine phosphoribosyltransferase reveals extensive conformational plasticity throughout the catalytic cycle. J. Mol. Biol., 2005, 351 (1), 170-181. 
[56] Eads, J. C.; Scapin, G.; Xu, Y.; Grubmeyer, C.; Sacchettini, J. C. The crystal structure of human hypoxanthine-guanine phosphoribosyltransferase with bound GMP. Cell, 1994, 78 (2), 325-334.

[57] Shi, W.; Li, C. M.; Tyler, P. C.; Furneaux, R. H.; Cahill, S. M.; Girvin, M. E.; Grubmeyer, C.; Schramm, V. L.; Almo, S. C. The $2.0 \AA$ structure of malarial purine phosphoribosyltransferase in complex with a transition-state analogue inhibitor. Biochemistry, 1999, 38(31), 9872-9880.

[58] Freymann, D. M.; Wenck, M. A.; Engel, J. C.; Feng, J.; Focia, P. J.; Eakin, A. E.; Craig, S. $\mathrm{P}^{\text {3rd }}$. Efficient identification of inhibitors targeting the closed active site conformation of the HPRT from Trypanosoma cruzi. Chem. Biol., 2000, 7(12), 957-968.

[59] Medrano, F. J.; Wenck, M. A.; Engel, J. C.; Craig, S. P ${ }^{3 \text { rd }}$. Analysis of 6-(2,2-dichloroacetamido)chrysene interaction with the hypoxanthine phosphoribosyltransferase from Trypanosoma cruzi. J. Med. Chem., 2003, 46(12), 2548-2550.

[60] Somoza, J. R.; Skillman, A. G.; Munagala, N. R.; Oshiro, C. M.; Knegtel, R. M. A.; Mpoke, S.; Fletterick, R. J.; Kuntz, I. D.; Wang, C. C. Rational design of novel antimicrobials: Blocking purine salvage in a parasitic protozoan. Biochemistry, 1998, 37(16), 53445348.

[61] Aronov, A. M.; Munagala, N. R.; Ortiz De Montellano, P. R.; Kuntz, I. D.; Wang, C. C. Rational design of selective submicromolar inhibitors of Tritrichomonas foetus hypoxanthine-guaninexanthine phosphoribosyltransferase. Biochemistry, 2000, 39(16), 4684-4691.

[62] Aronov, A. M.; Munagala, N. R.; Kuntz, I. D.; Wang, C. C. Virtual screening of combinatorial libraries across a gene family: in search of inhibitors of Giardia lamblia guanine phosphoribosyltransferase. Antimicrob. Agents Chemother., 2001, 45(9), 2571-2576.

[63] Fernandez, D.; Wenck, M. A.; Craig, S. P P $^{3 r d}$ Delfino, J. M. The purine transferase from Trypanosoma cruzi as a potential target for bisphosphonate-based chemotherapeutic compounds. Bioorg. Med. Chem. Lett., 2004, 14(17), 4501-4504.

[64] Madrid, D. C.; Ting, L. M.; Waller, K. L.; Schramm, V. L.; Kim, K. Plasmodium falciparum purine nucleoside phosphorylase is critical for viability of malaria parasites. J. Biol. Chem., 2008, 283(51), 35899-35907.

[65] Clayman, C. B.; Arnold, J.; Hockwald, R. S.; Yount, E. H. Jr.; Edgcomb, J. H.; Alving, A. S. Toxicity of primaquine in caucasians. J. Am. Med. Assoc., 1952, 149(17), 1563-1568.

[66] de Villiers, K. A.; Marques, H. M.; Egan, T. J. The crystal structure of halofantrine-ferriprotoporphyrin IX and the mechanism of action of arylmethanol antimalarials. J. Inorg. Biochem., 2008, 102(8), 1660-1667.

[67] Hughes, W.; Leoung, G.; Kramer, F.; Bozzette, S. A.; Safrin, S.; Frame, P.; Clumeck, N.; Masur, H.; Lancaster, D.; Chan, C.; Lavelle, J.; Rosenstock, J.; Falloon, J.; Feinberg, J.; Lafon, S.; Rogers, M.; Sattler, F. Comparison of atovaquone $(566 \mathrm{c} 80)$ with trimethoprim-sulfamethoxazole to treat pneumocystis carinii pneumonia in patients with AIDS. N. Engl. J. Med., 1993, 328(21), 1521-1527.

[68] Efferth, T.; Kaina, B. Toxicity of the antimalarial artemisinin and its dervatives. Crit. Rev. Toxicol., 2010, 40(5), 405-421.

[69] O'Neill, P. M.; Barton, V. E.; Ward, S. A. The molecular mechanism of action of artemisinin-The debate continues. Molecules, 2010, 15(3), 1705-1721.

[70] Griffith, K. S.; Lewis, L. S.; Mali, S.; Parise, M. E. Treatment of malaria in the United States - A systematic review. J. Am. Med. Assoc., 2007, 297 (20), 2264-2277.

[71] Dahl, E. L.; Shock, J. L.; Shenai, B. R.; Gut, J.; DeRisi, J. L.; Rosenthal, P. J. Tetracyclines specifically target the picoplast of the malaria parasite Plasmodium falciparum. Antimicrob. Agents Chemother., 2006, 50(9), 3124-3131.

[72] Chulay, J. D.; Watkins, W. M.; Sixsmith, D. G. Synergistic antimalarial activity of pyrimethamine and sulfadoxine against Plasmodium falciparum in vitro. Am. J. Trop. Med. Hyg., 1984, 33(3), 325-330.
[73] Werner, A.; Siems, W.; Schmidt, H.; Rapoport, I.; Gerber, G. Determination of nucleotides, nucleosides and nucleobases in cells of different complexity by reversed phase and ion pair high performance liquid chromatography. J. Chromatogr., Biomed. Appl., 1987, 421(2), 257-265.

[74] Heroux, A.; White, E. L.; Ross, L. J.; Kuzin, A. P.; Borhani, D. W. Substrate deformation in a hypoxanthine-guanine phosphoribosyltransferase ternary complex: The structural basis for catalysis. Structure, 2000, 8(12), 1309-1318.

[75] Naguib, F. N. M.; Iltzsch, M. H.; Elkouni, M. M.; Panzica, R. P.; Elkouni, M. H. Structure activity relationships for the binding of ligands to xanthine or guanine phosphoribosyltransferase from Toxoplasma gondii. Biochem. Pharmacol., 1995, 50(10), 16851693.

[76] Keough, D. T.; Ng, A. L.; Winzor, D. J.; Emmerson, B. T.; de Jersey, J. Purification and characterization of Plasmodium falciparum hypoxanthine-guanine-xanthine phosphoribosyltransferase and comparison with the human enzyme. Mol. Biochem. Parasitol., 1999, 98(1), 29-41.

[77] Olsen, A. S.; Milman, G. Chinese hamster hypoxanthine-guanine phosphoribosyltransferase. Purification, structural, and catalytic properties. J. Biol. Chem., 1974, 249(13), 4030-4037.

[78] Allen, T.; Henschel, E. V.; Coons, T.; Cross, L.; Conley, J.; Ullman, B. Purification and characterization of the adenine phosphoribosyltransferase and hypoxanthine-guanine phosphoribosyltransferase activities from Leishmania donovani. Mol. Biochem. Parasitol., 1989, 33(3), 273-281.

[79] Hochstadt, J., Hypoxanthine phosphoribosyltransferase and guanine phosphoribosyltransferase from enteric bacteria. Methods Enzymol., 1978, 51, 549-558.

[80] Guddat, L. W.; Vos, S.; Martin, J. L.; Keough, D. T.; de Jersey, J. Crystal structures of free, IMP-, and GMP-bound Escherichia coli hypoxanthine phosphoribosyltransferase. Prot. Sci., 2002, 11(7), 1626-1638.

[81] Aldritt, S. M.; Wang, C. C. Purification and characterization of guanine phosphoribosyltransferase from Giardia lamblia. J. Biol. Chem., 1986, 261(18), 8528-8533.

[82] Page, J. P.; Munagala, N. R.; Wang, C. C. Point mutations in the guanine phosphoribosyltransferase from Giardia lamblia modulate pyrophosphate binding and enzyme catalysis. Eur. J. Biochem., 1999, 259(3), 565-571.

[83] Balendiran, G. K.; Molina, J. A.; Xu, Y. M.; Torres-Martinez, J.; Stevens, R.; Focia, P. J.; Eakin, A. E.; Sacchettini, J. C.; Craig, S. $\mathrm{P}^{3 \mathrm{rd}}$. Ternary complex structure of human HGPRTase, PRPP, $\mathrm{Mg}^{2+}$, and the inhibitor HPP reveals the involvement of the flexible loop in substrate binding Prot. Sci., 1999, 8(12), 2815-2815.

[84] Focia, P. J.; Craig, S. P $\mathrm{P}^{3 \mathrm{rd}}$; Eakin, A. E. Approaching the transition state in the crystal structure of a phosphoribosyltransferase. Biochemistry, 1998, 37(49), 17120-17127.

[85] Canyuk, B.; Medrano, F. J.; Wenck, M. A.; Focia, P. J.; Eakin, A. E.; Craig, S. $\mathrm{P}^{3 \mathrm{rd}}$. Interactions at the dimer interface influence the relative efficiencies for purine nucleotide synthesis and pyrophosphorolysis in a phosphoribosyltransferase. J. Mol. Biol., 2004, 335(4), 905-921.

[86] Shi, W.; Munagala, N. R.; Wang, C. C.; Li, C. M.; Tyler, P. C.; Furneaux, R. H.; Grubmeyer, C.; Schramm, V. L.; Almo, S. C. Crystal structures of Giardia lamblia guanine phosphoribosyltransferase at 1.75 ̊․ Biochemistry, 2000, 39(23), 6781-6790.

[87] Monzani, P. S.; Trapani, S.; Thiemann, O. H.; Oliva, G. Crystal structure of Leishmania tarentolae hypoxanthine-guanine phosphoribosyltransferase. BMC Struct. Biol., 2007, 7, 59.

[88] Vos, S.; Parry, R. J.; Burns, M. R.; de Jersey, J.; Martin, J. L. Structures of free and complexed forms of Escherichia coli xanthine-guanine phosphoribosyltransferase. J. Mol. Biol., 1998, 282(4), 875-889.

[89] Vos, S.; de Jersey, J.; Martin, J. L. Crystal structure of Escherichia coli xanthine phosphoribosyltransferase. Biochemistry, 1997, $36(14), 4125-4134$. 